\title{
Arginine and Polyamines Fate in Leishmania Infection
}

\author{
Sandra M. Muxel'1*, Juliana I. Aoki', Juliane C. R. Fernandes ${ }^{1}$, Maria F. Laranjeira-Silva', \\ Ricardo A. Zampieri' ${ }^{1}$, Stephanie M. Acuña ${ }^{1}$, Karl E. Müller ${ }^{2}$, Rubia H. Vanderlinde ${ }^{1}$ and \\ Lucile M. Floeter-Winter ${ }^{\text {* }}$
}

'Department of Physiology, Institute of Biosciences, University of São Paulo, São Paulo, Brazil, ${ }^{2}$ Department of Clinical Science, University of Bergen, Bergen, Norway

Leishmania is a protozoan parasite that alternates its life cycle between the sand fly and the mammalian host macrophages, involving several environmental changes. The parasite responds to these changes by promoting a rapid metabolic adaptation through cellular signaling modifications that lead to transcriptional and post-transcriptional gene expression regulation and morphological modifications. Molecular approaches such as gene expression regulation, next-generation sequencing (NGS), microRNA (miRNA) expression profiling, in cell Western blot analyses and enzymatic activity profiling, have been used to characterize the infection of murine BALB/c and C57BL/6 macrophages, as well as the human monocytic cell-lineage THP-1, with Leishmania amazonensis wild type ( $(\mathrm{La}-\mathrm{WT})$ or arginase knockout $\left(\mathrm{La}^{-\mathrm{arg}^{-}}{ }^{-}\right.$. These models are being used to elucidate physiological roles of arginine and polyamines pathways and the importance of arginase for the establishment of the infection. In this review, we will describe the main aspects of Leishmania-host interaction, focusing on the arginine and polyamines pathways and pointing to possible targets to be used for prognosis and/or in the control of the infection. The parasite enzymes, arginase and nitric oxide synthase-like, have essential roles in the parasite survival and in the maintenance of infection. On the other hand, in mammalian macrophages, defense mechanisms are activated inducing alterations in the mRNA, miRNA and enzymatic profiles that lead to the control of infection. Furthermore, the genetic background of both parasite and host are also important to define the fate of infection.

\section{Keywords: promastigote, amastigote, L-arginine, ornithine, polyamine pathway, nitric oxide, arginase, nitric oxide synthase}

\begin{abstract}
Abbreviations: AAP3, amino acid permease 3; ADC, arginine decarboxylase; AdoMetDC, adenosylmethionine decarboxylase; AOCT, $\mathrm{N}$-acetylornithine carbamoyltransferase; AOD, acetylornithine deacetylase; ARG, arginase; ASL, argininosuccinate lyase; ASS, argininosuccinate synthase; CAT, cationic amino acid transporter; CL, cutaneous leishmaniasis; CP, carbamoyl phosphate; CPS, carbamoyl phosphate synthetase; DAMP, danger-associated molecular pattern; DFMO, difluoromethylornithine; G5K, glutamate 5-kinase; G5SDH, glutamate-5-semialdehyde dehydrogenase; GspS, glutathionylspermidine synthase; La, L. amazonensis; Ld, L. donovani; IFN, interferon; IL, interleukin; ML, mucosal leishmaniasis; MPK2, mitogen protein kinase 2; mRNA, messenger RNA; miRNA, microRNA; NGS, next-generation sequencing; NO, nitric oxide; NOS, nitric oxide synthase; OAT, ornithine aminotransferase; OCD, ornithine cyclodeaminase; ODC, ornithine decarboxylase; ORF, open reading frame; OTA, ornithine transacetylase; OTC, ornithine transcarbamylase; P5C, pyrroline-5-carboxylate; P5CDH, pyrroline-5-carboxylate dehydrogenase; P5CR, pyrroline-5-carboxylate reductase; PAMP, pathogen-associated molecular pattern; PD, proline dehydrogenase; PEN, pentamidine; PR, proline racemase; PRR, pattern recognition receptor; ROS, reactive oxygen species; SGDS, succinylglutamate desuccinylase; SpdS, spermidine synthase; SpmS, spermine synthase; TLR, toll-like receptor; TNF, tumor necrosis factor; TryS, trypanothione synthase; UTR, untranslated region; VL, visceral leishmaniasis; WHO, World Health Organization.
\end{abstract}




\section{INTRODUCTION}

The leishmaniases consist of a wide spectrum of diseases caused by more than 20 different species of the protozoa belonging to the Leishmania genus (Marsden, 1986; Ashford, 2000) and considered by the WHO as an important public health problem and a neglected tropical disease (WHO, 2017). The infection can generate several clinical manifestations ranging from cutaneous and mucocutaneous lesions to the lethal VL (Ashford, 2000). The disease is endemic in 98 countries around the world, with the annual incidence for CL estimated to be 0.7-1.2 million and 0.2-0.4 million for VL (Alvar et al., 2012). Leishmania has a dimorphic life cycle alternating between the foregut and proboscis (stomodeal valve) of the sand fly (Phlebotomus in Africa, Europe and Asia and Lutzomyia in the Americas). The replicative procyclic promastigotes form (foregut) differentiates to the infective metacyclic promastigotes and migrates to the insect stomodeal valve. The amastigote forms appear in the interior of the phagolysosomal compartment in the mammalian host macrophage (Sacks and Kamhawi, 2001; Teixeira et al., 2013).

Since the 1970's, L-arginine has been described as an essential amino acid for Leishmania promastigote cultivation and growth (Krassner and Flory, 1971; Steiger and Meshnick, 1977; Steiger and Steiger, 1977). Later, L-arginine was also described as essential for Leishmania amastigotes survival and defining the fate of the infection in the host-parasite interaction (Wanasen et al., 2007; Wanasen and Soong, 2008). As L-arginine cannot be synthesized de novo (Landfear, 2011), the parasite developed complex mechanisms to take up this amino acid by specific transporters and control L-arginine availability (Darlyuk et al., 2009; Goldman-Pinkovich et al., 2016; Aoki et al., 2017a). This amino acid is the precursor in the synthesis of proteins, urea, ornithine, citrulline, nitric oxide (NO), creatinine, agmatine, glutamate, proline, putrescine, spermidine and spermine. On the other hand, L-arginine can be used to produce $\mathrm{NO}$ in macrophages, activate the immune response (Pekarova and Lojek, 2015) and promote the parasite killing (Roberts et al., 2004; Laranjeira-Silva and Floeter-Winter, 2014).

In this review, we will describe the main aspects of $\mathrm{L}$-arginine uptake and metabolism in both parasite and host. Each section will describe the molecule that participate and modulate the main pathways where the amino acid can be found, pointing to possible targets for infection control.

\section{Leishmania L-ARGININE UPTAKE}

Leishmania is auxotrophic for many amino acids, including L-arginine. Therefore, the parasite has developed a complex and specific machinery to take up the exogenous source necessary for its replication and growth (Camargo et al., 1978; Roberts et al., 2004). The control of L-arginine levels depends on the selective uptake, as well as the intracellular concentration (Vieira and Cabantchik, 1995; Vieira, 1998). Plasma membrane permeases, as well as $\mathrm{H}^{+}$-pumps are responsible for the arginine uptake (Zilberstein, 1993; Vieira and Cabantchik, 1995; Geraldo et al., 2005; Shaked-Mishan et al., 2006; McConville et al., 2007; Naderer and McConville, 2008; Darlyuk et al., 2009; Castilho-Martins et al., 2011). It has been shown that to control the intracellular pool of L-arginine, glutamate and methionine, L. amazonensis is able to sense the external availability of amino acids (CastilhoMartins et al., 2015). Another factor that can regulate the L-arginine uptake is its consumption by ARG activity. The L-arginine amount increases in the absence of ARG activity (Castilho-Martins et al., 2015). Also, intracellular amastigotes can scavenge essential amino acids from the phagolysosome (McConville et al., 2007, 2015; McConville, 2016).

Several studies have described the molecular and functional characteristics of the amino acid permeases (AAP), as a high affinity transporter of L-arginine in L. donovani (Zilberstein, 1993; Zilberstein and Gepstein, 1993; Kandpal et al., 1995; Akerman et al., 2004; Geraldo et al., 2005; Shaked-Mishan et al., 2006; Darlyuk et al., 2009), L. amazonensis, L. infantum, and L. major (Geraldo et al., 2005; Shaked-Mishan et al., 2006; Castilho-Martins et al., 2011; Aoki et al., 2017a). The aap3 coding sequence is present in two copies, organized in tandem, in the genome of L. donovani (3.1 and 3.2 copies) (ShakedMishan et al., 2006; Darlyuk et al., 2009) and in L. amazonensis (5.1 and 4.7 copies) (Castilho-Martins et al., 2011). The ORF shows 98\% identity between the two copies and 93\% identity between L. donovani and L. amazonensis AAP3 (Shaked-Mishan et al., 2006; Castilho-Martins et al., 2011). For L. donovani, the $3^{\prime} \mathrm{UTR}$ is completely different between the two copies (Darlyuk et al., 2009). A possible explanation for two copies can be related to the post-transcriptional gene regulation according to the environmental conditions, since the two ORFs are similar. In silico analyses in TriTrypDB and GenBank databases has shown aap3 orthologs in the genome of L. infantum, L. major, L. mexicana, L. gerbilli, L. tropica, L. turanica, L. panamensis, L. braziliensis, and L. aethiopica (Aoki et al., 2017a).

Ld-AAP3 mediates the uptake of L-arginine, lysine, histidine, phenylalanine and citrulline, with higher affinity for L-arginine (Kandpal et al., 1995; Shaked-Mishan et al., 2006). It does not promote the eflux of the intracellular L-arginine (Kandpal et al., 1995). The $N$-methyl + arginine acetate and phospho$\mathrm{L}$-arginine compete with L-arginine uptake indicating a stereospecific transporter by recognition of both guanidino group and the arginine side chain, while L-arginine analogs, nitroL-arginine methyl ester, $N$-nitro-L-arginine, aminoguanidine, agmatine and o-arginine do not modify L-arginine uptake (Kandpal et al., 1995).

Under L-arginine starvation, L. donovani senses the lack of the amino acid availability and responds with rapid upregulation of the expression and activity of Ld-AAP3 (Goldman-Pinkovich et al., 2016). The L-arginine starvation in L. donovani promastigotes, axenic amastigotes or intracellular amastigotes also lead to up-regulation of mitogen-activated protein kinase 2 (MPK2), suggesting that the parasite monitor the L-arginine availability (Goldman-Pinkovich et al., 2016). In addition, temperature change during promastigote to amastigote differentiation $\left(25^{\circ} \mathrm{C}\right.$ and $34^{\circ} \mathrm{C}$, respectively) alters the amount 
of the La-aap3 5.1 transcript as well as protein expression, the localization profile in the plasma membrane and L-arginine uptake in L. amazonensis promastigotes. However, Aoki et al. (2017a) observed no difference in expression of the La-aap3 4.7 transcript as opposed to the 5.1 copy, indicating that for L. amazonensis, the 5.1 copy of the aap3 gene is the one presenting the regulatory sequences for modulating the expression under different conditions (Aoki et al., 2017a).

The absence of enzymes involved in the polyamines biosynthesis, such as ARG (Castilho-Martins et al., 2015), ODC or SpdS (Darlyuk et al., 2009) reduce L-arginine uptake in L. amazonensis and L. donovani. Furthermore, the ARG absence upregulated the amino acid transporter aATP11 (Aoki et al., 2017a). Supplementation of $L$. donovani promastigote culture with putrescine reduced the L-arginine uptake, but increased the intracellular pool of L-arginine and did not affect ornithine pool. However, spermidine supplementation, reduced both L-arginine transport and the intracellular pool and ornithine levels (Darlyuk et al., 2009). The absence of ODC activity in parasites submitted to putrescine supplementation reduced the internal pool of L-arginine and maintained ornithine content, but the absence of SpdS activity reduced the internal pool of both L-arginine and ornithine (Darlyuk et al., 2009). Even with decreased L-arginine uptake, the absence of ODC and SpdS activities did not effect in abundance of the Ld-AAP3 protein (Darlyuk et al., 2009). The absence of ARG activity in L. amazonensis promastigotes maintained in a putrescine-containing medium lead to an increase in the internal pool of L-arginine, reduction in La-aap3 transcripts and reduction of ornithine levels (Castilho-Martins et al., 2015).

The importance of L-arginine availability and ARG activity has also been described in intracellular amastigotes from in vitro infections with macrophages obtained from different organisms and genetic backgrounds, such as $\mathrm{BALB} / \mathrm{c}$ and $\mathrm{C} 57 \mathrm{BL} / 6$ mice strains and human THP-1-derived macrophages. In LeishmaniaBALB/c and Leishmania-THP-1 macrophage infections, the La-aap3 5.1 copy is upregulated during the time course of infection with L. amazonensis (Aoki et al., 2017a; Muxel et al., 2017). In contrast, in Leishmania-C57BL/6 macrophage infection, $L a$-aap3 5.1 is not regulated during the time course of infection with or without ARG activity (Aoki et al., 2017a). In the absence of ARG activity, both La-aap3 5.1 and 4.7 copies appear up-regulated after $4 \mathrm{~h}$ of Leishmania-THP-1 infection. These differential behaviors can be explained by the distinct background of the host that can influence the L-arginine uptake and/or accumulation (Aoki et al., 2017a). Additionally, the lower availability of L-arginine in melatonin-treated BALB/C macrophage infected with $L$. amazonensis, maintained the levels of La-aap3 5.1 and arg expression to keep the polyamine supply (Laranjeira-Silva et al., 2015).

To summarize, Leishmania senses the L-arginine availability depending on its ARG activity. The parasite also modulates the L-arginine uptake by aap3 expression or other amino acid transporters (Goldman-Pinkovich et al., 2016; Aoki et al., 2017a). The AAP3 localization in the plasma membrane in L. donovani (Goldman-Pinkovich et al., 2016) and L. amazonensis (Aoki et al., 2017a) is directly related to this sensing mechanism. In addition, the AAP3 localization in the glycosome indicates a direct transport of the amino acid to this organelle (Hart et al., 1987; Opperdoes, 1987; Opperdoes and Szikora, 2006; GoldmanPinkovich et al., 2016; Aoki et al., 2017a).

\section{Leishmania L-ARGININE METABOLISM}

Besides the L-arginine uptake, Leishmania also express enzymes involved in the L-arginine metabolism, including ARG and ODC, as part of the urea cycle and also, enzymes involved in the polyamines production, such as SpdS and SpmS. Since 1978, urea production has been characterized in many Leishmania species, and ARG activity has been highlighted as crucial for supplying ornithine for polyamines production, essential for parasite replication and the establishment of infection (Camargo et al., 1978; Mukhopadhyay and Madhubala, 1995). On the other hand, some Leishmania species, such as L. braziliensis, express other enzymes that produce urea using L-arginine, arginine deaminase and citrulline hydrolase (Yoshida and Camargo, 1978).

The Leishmania pathways involving L-arginine are demonstrated in the Figure 1. L-arginine is hydrolyzed by ARG to produce urea and ornithine in the first step of the polyamine pathway. Then, ornithine is decarboxylated by ODC to produce putrescine, which is substrate for spermidine and spermine production by SpdS and SpmS, respectively, adding an aminopropyl group from decarboxylated $S$-adenosylmethionine (dAdoMet) (Wu and Morris, 1998; Basselin et al., 2000; Roberts et al., 2001, 2002; Gilroy et al., 2011; da Silva et al., 2012). In addition, Leishmania also uses L-arginine to produce NO and citrulline (Genestra et al., 2006b; Sarkar et al., 2011; Castilho-Martins et al., 2015).

ARG is a metalloenzyme that requires two manganese atoms for enzymatic activity and uses a water molecule to attack the L-arginine substrate (Kanyo et al., 1996; da Silva et al., 2008). The ARG expression has been used as genus identification and classification tool in parasitic protozoa of Trypanosomatidae family, such as Leishmania genus (Camargo et al., 1978; Yoshida and Camargo, 1978). da Silva et al. (2002) described the molecular characterization of the ARG-encoding gene and its genomic organization in L. amazonensis, L. major, and L. mexicana.

ARG is compartmentalized in the glycosome of promastigotes and amastigotes, as identified for L. amazonensis, L. mexicana and L. donovani (Hart et al., 1987; Opperdoes, 1987; Roberts et al., 2004; Opperdoes and Szikora, 2006; da Silva et al., 2008; Laranjeira-Silva et al., 2012; D’Antonio et al., 2013; Boitz et al., 2017). The glycosomal localization of ARG is crucial for its activity in amastigotes of L. amazonensis and L. mexicana, since the mislocation of the enzyme reduced in vitro and in vivo infectivity, emphasizing the importance of this localization for proper ARG function (Roberts et al., 2004; Laranjeira-Silva et al., 2012; Laranjeira-Silva and Floeter-Winter, 2014; Boitz et al., 2017). In addition, L. amazonensis axenic amastigotes present a down-regulated ARG expression when compared to promastigotes (Aoki et al., 2017b). However, an increase of ARG expression in intracellular amastigotes during the time course of 


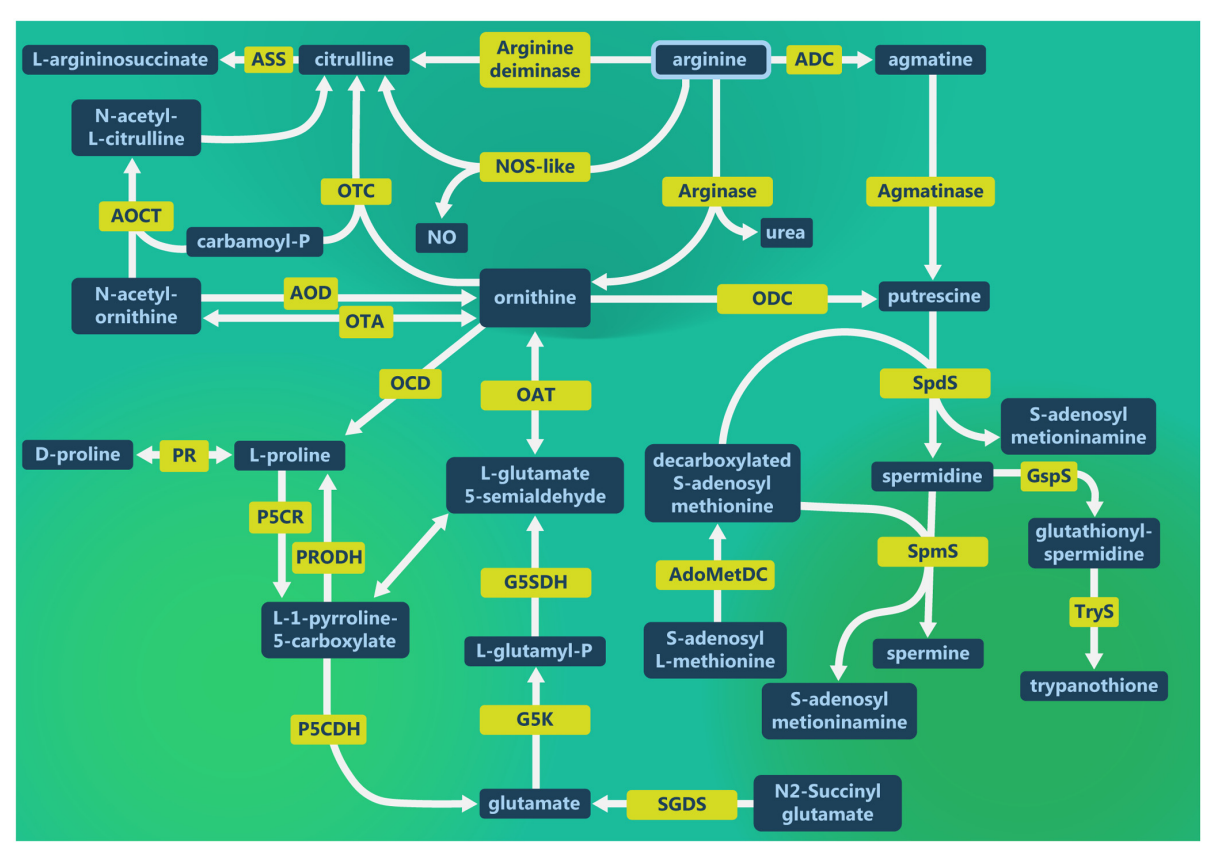

FIGURE 1 | Leishmania L-arginine metabolism. L-arginine metabolic pathways in Leishmania to produce polyamines as well as the interconnection with glutamate and proline metabolism. L-arginine supplies citrulline and nitric oxide (NO) production. Ornithine supplies proline, glutamate and putrescine production, as well as the interconvertion of glutamate, proline and ornithine. Putrescine is the first polyamine that can form spermidine and spermine, essential for parasite growth. Spermidine is the substrate for spermine and trypanothione production. $A D C$, arginine decarboxylase; $A O C T, N$-acetylornithine carbamoyltransferase; AOD, acetylornithine deacetylase; AdoMetDC, adenosylmethionine decarboxylase; ASS, argininosuccinate synthase; G5K, glutamate 5-kinase; G5SDH, glutamate-5-semialdehyde dehydrogenase; GspS, glutathionylspermidine synthase; NOS-like, nitric oxide synthase-like; OAT, ornithine aminotransferase; OCD, ornithine cyclodeaminase; ODC, ornithine decarboxylase; OTA, ornithine transacetylase; OTC, ornithine transcarbamylase; P5CDH, pyrroline-5-carboxylate dehydrogenase; P5CR, pyrroline 5-carboxilate reductase; PRODH, proline dehydrogenase; PR, proline racemase; SGDS, succinylglutamate desuccinylase; SpdS, spermidine synthase; SpmS, spermine synthase and Trys, trypanothione synthase.

$\mathrm{BALB} / \mathrm{c}$ macrophages infection was observed in L. amazonensis (Muxel et al., 2017). These data reinforce the existence of different modulation of ARG expression under environment conditions, such as axenic cultivation of parasites.

Metabolomic data from L. amazonensis promastigotes indicate that the absence of ARG activity increased the levels of the intracellular pool of L-arginine, citrulline and L-glutamate 5-semialdehyde and reduced proline, aspartate, ornithine, and putrescine, but spermidine and spermine levels were not altered (Castilho-Martins et al., 2015). RNA-seq data support the idea that by modulating the expression of enzymes involved in consumption and production of metabolites from L-arginine, L. amazonensis is able to surpass the absence of ARG activity (Aoki et al., 2017b).

Despite the lower levels of L-arginine, starved promastigotes increase the citrulline levels, reduce ornithine and putrescine levels and maintain the production of urea and agmatine. Ornithine can be used to produce citrulline through OTC that catalyzes the reaction between ornithine and carbamoyl phosphate (CP) (Figure 1). This last compound is produced from bicarbonate/ammonia and ATP $\left(\mathrm{NH}_{3} / \mathrm{HCO}_{3}{ }^{-} / \mathrm{ATP}\right)$ through CPS. Furthermore, a lower level of AOD transcripts in $\mathrm{La}$-arg- ${ }^{-}$may reduce the conversion of N2-acetylornithine in ornithine (Castilho-Martins et al., 2015; Aoki et al., 2017b).
The increase in citrulline levels in $\mathrm{La}$-arg ${ }^{-}$can be due to the conversion of L-arginine in NO and citrulline via NOS-like activity (Genestra et al., 2003; Genestra et al., 2006a,b; Sarkar et al., 2009; Sarkar et al., 2011; Acuña et al., 2017) or the conversion of citrulline via arginine deaminase. There are no reports of any functional activity of Leishmania arginine deaminase to produce citrulline from arginine. The sustenance of high level of citrulline can occur via the reduction in transcript levels of arginosuccinate synthase which thereby reduces the conversion of citrulline into argininosuccinate (Aoki et al., 2017b). As L-arginine cannot be de novo synthesized in Leishmania (Landfear, 2011), implicating in the control of internal L-arginine availability by parasite transporters for its survival (Mandal et al., 2016). Yet, ASS activity converting citrulline to arginosuccinate has been demonstrated. It seems that ASS activity is not related with L-arginine synthesis, but with important biological functions of arginosuccinate in the establishment of the infection (Lakhal-Naouar et al., 2012; Sardar et al., 2016).

Even with the reduction in putrescine levels and SpdS transcripts, the levels of spermidine and spermine are maintained (Castilho-Martins et al., 2015). Spermine supplementation did not rescue ODC knockout L. donovani, and spermidine supplementation did not rescue ARG knockout L. donovani (Boitz et al., 2017). These observations show that interconversion 
of spermine to spermidine and putrescine do not occur, supporting that putrescine and spermidine are critical for the survival and the growth of the parasite (Roberts et al., 2001; Boitz et al., 2017).

Spermidine provides the production of trypanothione, an important regulator of intracellular thiol redox balance. Trypanothione also acts in the detoxification of hydroperoxide and other stressing chemical oxidant, via the enzymes glutathionylspermidine synthetase (GspS) and glutathionylspermidine-dependent trypanothione synthetase (TryS) (Tovar et al., 1998; Krauth-Siegel et al., 2003; Oza et al., 2005).

$\mathrm{L}$-arginine can be used to produce agmatine through arginine descarboxylase (ADC) activity and agmatine can be converted in putrescine via agmatinase (Figure 1). The transcripts of ADC and agmatinase have been described in L. mexicana and L. amazonensis (Fiebig et al., 2015; Aoki et al., 2017b) and the presence of agmatine in L. amazonensis (Castilho-Martins et al., 2015).

L-arginine is also used by promastigotes of L. braziliensis, L. chagasi, L. donovani, L. donovani, L. infantum, L. major, L. mexicana and L. panamensis to produce NO (Sarkar et al., 2011). In L. amazonensis L-arginine is used to produce both NO and citrulline (Genestra et al., 2003, 2006a,b; Sarkar et al., 2011; Castilho-Martins et al., 2015). Furthermore, high levels of NO production correlate with high amounts of the infective metacyclic forms in promastigote culture of L. amazonensis (Genestra et al., 2006b). The differentiation to axenic amastigotes elevates the amount of NO in L. amazonensis compared to promastigotes (Temporal et al., 2005). Higher levels of citrulline in absence of ARG activity can be the result of the conversion of L-arginine to NO and citrulline via NOS-like activity (Genestra et al., 2006a,b; Sarkar et al., 2009; Sarkar et al., 2011; Acuña et al., 2017). NO concentration defines its biological function and in this case, NO can act in post-translational modifications, such as $S$-nitrosylation and tyrosine nitration (Colasanti et al., 2002; Kawasaki et al., 2011; Martinez-Ruiz et al., 2011; Pereira et al., 2015). It can also interfere with several biological processes, such as PKC signaling, cytochrome c regulation of caspasecascade inactivation, protein degradation and control of the redox environment, increasing the resistance to toxicity signals into macrophage (Souza et al., 2000; Balafanova et al., 2002; Ji et al., 2006; Nakagawa et al., 2007; Abello et al., 2009; Hess and Stamler, 2012). Certainly, NO is important to metacyclogenesis and amastigote differentiation (Acuña et al., 2017) and more studies are needed to elucidate the role of $\mathrm{NO}$ production by promastigotes and amastigotes forms.

Altogether, the internal pool of L-arginine, ornithine, and putrescine is altered in function of external availability of L-arginine, even with higher levels of ornithine than L-arginine and putrescine. ARG and ODC activity, as well as the rate and production capacity of enzymes of the polyamines pathways are linked to the fine-tuning capacity of Leishmania to sense the external environment. This way, the changes from the mid-gut of sand fly to phagolysosome of mammalian host cell can be sensed by promastigotes or intracellular amastigotes allowing the maintenance of cellular homeostasis.
In addition, L-arginine starvation promotes an externalization of phospholipids that bind to Annexin- $\mathrm{V}$ signaling the apoptosislike cell death in L. donovani, which could be blocked by L-arginine, ornithine or putrescine supplementation (Mandal et al., 2016). The change in the phospholipids externalization occurs during nutrients starvation in promastigote in vitro growth curve and in metacyclogenesis (Weingartner et al., 2012; dos Santos et al., 2013) influencing the Leishmania infectivity (de Freitas Balanco et al., 2001; van Zandbergen et al., 2006; Wanderley et al., 2009).

\section{Leishmania PROLINE AND GLUTAMATE METABOLISM}

L-arginine is one of the most versatile amino acids. It can be hydrolyzed by ARG to produce ornithine and urea, as well as its interconversion into the amino acids proline and glutamate can improve the polyamines production and enable a multi-metabolic fate during parasite growth and differentiation.

Proline and 1-pyrroline-5-carboxylate (P5C) play multifaceted roles in the cellular physiology of mammalian cells. The proline pathways, to the production of polyamines, include the interconversion between proline and $\mathrm{P} 5 \mathrm{C}$, by proline dehydrogenase (PRODH) and pyrroline 5-carboxylate reductase (P5CR). Proline can act as a redox shuttle being oxidized in mitochondria or, still, linked with other metabolic pathways, as pentose phosphate (O'Quinn et al., 2002; Kaul et al., 2008; $\mathrm{Wu}$ et al., 2008). In addition, glutamate and its metabolites, such as P5C, L-glutamyl-P and L-glutamate 5-semihaldehyde, are multipurpose molecules serving as precursors of L-proline, L-ornithine, and L-arginine. Furthermore, glutamate and its metabolites help to protect cells from nutrient depletion, oxidative stress and tumor stress (Wakabayashi et al., 1991a,b; Shanware et al., 2011).

Ornithine can form L-proline via OCD, by a $\mathrm{NAD}^{+}$dependent hydride transfer reaction that culminates in ammonia elimination in mammalian cells. D-proline can be converted to L-proline by $\mathrm{PR}$, a reversible reaction. L-proline form $\mathrm{P} 5 \mathrm{C}$ by P5CR. Still, P5C can be converted in L-proline by PRODH. P5C form glutamate by $\mathrm{P} 5 \mathrm{CDH}$. Ornithine can be interconverted to L-glutamate-5-semialdehyde (G5S) via OAT. Additionally, glutamate form L-glutamyl-P via L-glutamate-5-semialdehyde kinase (G5K), follow by G5SDH producing G5S. And G5S can be interconvert to $\mathrm{P} 5 \mathrm{C}$ by hydration reaction (Goodman et al., 2004; Wu et al., 2008). Castilho-Martins et al. (2015) found that amino acid starvation increased the intracellular pool of glutamate and methionine and decreased proline, ornithine and putrescine. This metabolite profile correlate with enzyme levels based on the following connections: reduction of proline due to $\mathrm{P} 5 \mathrm{C}$ by $\mathrm{P} 5 \mathrm{CR}$ and the increase of glutamate levels via conversion of $\mathrm{P} 5 \mathrm{C}$ through $\mathrm{P} 5 \mathrm{CDH}$ activity. The absence of ARG reduce the level of $\mathrm{P} 5 \mathrm{CDH}$ transcripts and increase the amount of P5CR transcript, explaining the consumption of proline to be converted to P5C (Figure 1) (Castilho-Martins et al., 2015; Aoki et al., 2017a). P5C is consumed to increase the levels of 
L-glutamate 5-semialdehyde, as well as the L-glutamyl-phosphate conversion by G5SDH (Castilho-Martins et al., 2015).

The spermidine and spermine synthesis are not reduced in amino acid starved promastigotes. This fact could be explained by the use of proline and/or glutamate to produce P5C/G5S and subsequently ornithine, citrulline and agmatine, partially helping the production of putrescine via conversion of agmatine by agmatinase to supply spermidine and spermine. In addition, increased levels of methionine can source the $S$-adenosyl L-methionine (AdoMet) formation through methionine adenosyltransferase that uses ATP. Also, AdoMetDC produces decarboxylated S-adenosyl methionine, an aminopropyl-donor molecule used together with putrescine to form spermidine and spermine.

\section{Leishmania-HOST INTERACTION}

In mammals, L-arginine metabolism can be analyzed at the whole organism level or cellular level. Its biosynthesis can instate inflammation or immune regulation during infections or at physiological steady state, respectively (Rath et al., 2014; Ribeiro-Gomes et al., 2014). In the initial steps of Leishmania infection, there is neutrophil and monocyte recruitment to the affected tissue leading to macrophage differentiation days after infection. This has implications for the recognition of the parasite, opsonization, phagocytosis and consequent induction of inflammatory response with NO production, ROS and pro-inflammatory responses by the mammal cells. These actions coordinate the innate immune response and parasite killing mechanisms, as showed for L. amazonensis, L. major and L. donovani (Nathan and Shiloh, 2000; Matte et al., 2001). However, Leishmania can escape from the anti-leishmanicidal mechanisms of macrophages, leading to amastigote differentiation and proliferation in the phagolysosome of the macrophage (Gregory and Olivier, 2005). In this evasion, the macrophage arginase (ARG1) is activated to provide substrate for polyamine pathways (Gregory and Olivier, 2005). The parasite shares the L-arginine intracellular pool with the macrophage.

Some studies have shown the importance of the PRRs in the initiation of the innate immune response, such as TLRs, that recognizes PAMPs or DAMPs (O’Neill et al., 2013). This recognition has implications on the susceptibility or resistance to Leishmania infection through the role of TLRs in the activation of the phagocyte. Recognition by TLRs induced antiparasitic activity and the production of pro-inflammatory cytokines, such as IL-1, IL-6, TNF, IL-12 e IFN- $\gamma$ (Akira and Sato, 2003; de Veer et al., 2003; Flandin et al., 2006; El Kasmi et al., 2008), which also could influence the rate of NOS2/ARG1 during infection.

Leishmania can induce adaptive immune responses via cytokines produced by $\mathrm{T} \mathrm{CD}^{+}$lymphocytes, which can be either polarized to Th1 or Th2 phenotype. Generally, Th2 cells producing IL-4, IL-10, and IL-13 cytokines are capable of inducing ARG1 activity in murine macrophages, leading to a M2 macrophage phenotype that results in NO reduction. This leads to susceptibility to L. major, L. amazonensis and L. donovani infection, as observed in BALB/c mice infections (Nasseri and Modabber, 1979; Corraliza et al., 1995; Bacellar et al., 2000; Bhattacharyya et al., 2001; Kane and Mosser, 2001; Yang et al., 2007). On the other hand, the resistance to infection is associated with Th1 response, with the production of TNF, IL-12 and IFN- $\gamma$ cytokines and induction of NOS2 expression with consequent $\mathrm{NO}$ production resulting in a M1 macrophage functional state, as observed in C57BL/6 mice infection (Ghalib et al., 1995; Vieira et al., 1996; Wilhelm et al., 2001; Yang et al., 2007; Ben-Othman et al., 2009; Srivastava et al., 2012). Besides, the resistance to L. donovani infection is related to IL-12 mediated Th1 cells activated via MyD88 (Janeway and Medzhitov, 2002; de Veer et al., 2003; Medzhitov, 2007). Also, chronic disease is associated to Th2 exacerbation in L. amazonensis, L. major and L. mexicana infection in BALB/c mice (Loeuillet et al., 2016).

In skin biopsies and plasma from patients with diffuse CL patients, higher levels of host ARG1 and ODC were detected as well as anti-inflammatory and/or suppressor factor, prostaglandin E2, IL-10 and TGF- $\beta$ (Melby et al., 1994; FrancaCosta et al., 2015). Lesions of patients with mucocutaneous leishmaniasis (ML) presents higher levels of IFN- $\gamma$ and lower levels of IL10R than CL patients, but similar levels of TNF- $\alpha$ and IL-10. The exacerbation of inflammation and cytotoxicity can promote tissue destruction. In this way, in lesions of CL patients, the increased levels of cells producing granzyme B correlates with lesion size and necrotic process (Santos et al., 2013). Some Leishmania molecules, such as lipophosphoglycan (LPG), seem to repress IL1- $\alpha$ (Frankenburg et al., 1990), IL-1- $\beta$ (Hatzigeorgiou et al., 1996) and IL-12 (Carrera et al., 1996; Belkaid et al., 1998; Weinheber et al., 1998) production during infection via TLR2. Indeed, Leishmania-LPG regulates negatively the TLR4 signaling via SOCS-1 (Nakagawa et al., 2002) and reduces TNF by induction of repressor genes, such as SOCS-1 and SOCS-3 (de Veer et al., 2003; Kavoosi et al., 2010; Faria et al., 2012). The increase in L-arginine uptake and ARG1 activity induces polyamines production, which correlates with the increase of IL-10 and reduction of IL-12 and TNF- $\alpha$ levels in L. donovani THP-1-derived macrophages infection (Mandal et al., 2017).

\section{Leishmania-HOST INTERACTION TARGETING L-ARGININE TRANSPORT AND METABOLISM}

Controlled uptake of nutrients and ions into cells is important to maintain the intracellular homeostasis, metabolic and physiological requirements and adaptation of parasite to a hostile environment. Leishmania infection induces both an increase in $\mathrm{L}$-arginine uptake and its hydrolysis to produce polyamines or the uptake of polyamines themselves by host cells (Bachrach et al., 1979; Schnur et al., 1979; Sacks and Kamhawi, 2001; da Silva et al., 2002, 2012; Teixeira et al., 2013; Séguin and Descoteaux, 2016), as showed in Figure 2. In infected macrophages, L-arginine is a common substrate for host NOS2 and ARG1 resulting in $\mathrm{NO}$ and citrulline production leading to parasite eradication or parasite replication via polyamine production, respectively. In addition, there are mechanisms for L-arginine uptake in both 


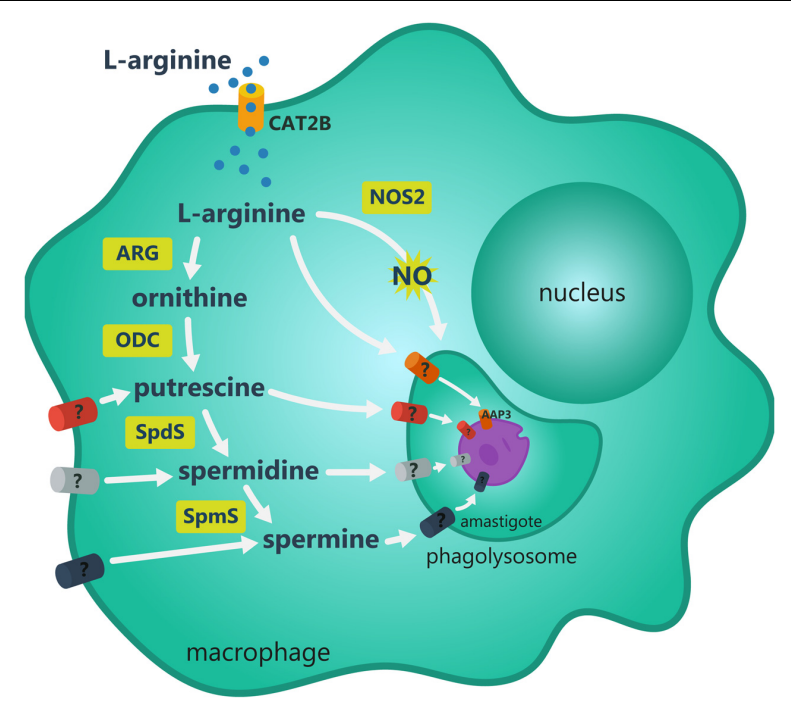

FIGURE 2 | Metabolic fate of L-arginine in Leishmania infected macrophage. $\mathrm{L}$-arginine uptake in the macrophage occurs mostly through CAT2B transporter. Once inside the macrophage, the amino acid is directed to nitric oxide (NO) or polyamines synthesis. NO is produced through NOS2 activity. Arginase (ARG) activity produces ornithine that is further decarboxylated by ornithine decarboxylase (ODC) producing putrescine, a substrate for spermidine synthase (SpdS) and spermine synthase (SpmS) producing spermidine and spermine, respectively. Some intermediate metabolites may cross phagolysossome and the parasite plasmatic membrane. These transporters have not been described yet. The L-arginine uptake occurs by amino acid permease 3 (AAP3) over the parasite plasmatic membrane and to glycosome for polyamines production by the parasite.

the phagolysosome and parasite membrane. Amastigotes can metabolize the amino acid to produce polyamines and/or can take up polyamines from host macrophage to replicate, also modifying the metabolism of host cell.

In mammalian cells, the endogenous synthesis of L-arginine from proline or glutamate via ornithine is not sufficient to supply the various pathways that need this amino acid as precursor, highlighting the importance of L-arginine uptake via cationic amino acid transporters (CAT1, CAT2A, CAT2B, CAT3) that differ in affinity to L-arginine, ornithine, histidine and lysine (Closs et al., 2004, 2006) Therefore, the control of L-arginineuptake is an important factor to elicit the macrophage responses against Leishmania (Liew et al., 1990; Iniesta et al., 2001). Th1 cytokines production, such as TNF $\alpha$ and IFN- $\gamma$, induce macrophages to increase L-arginine uptake mainly via CAT2B and NO production by NOS2 leading to parasite death (Green et al., 1990a,b; Liew et al., 1991; Yeramian et al., 2006a,b; Wanasen et al., 2007). Th2 cytokines also induce CAT2B, however, ARG1 activity deviate L-arginine to polyamines production, enabling the parasite survival and replication (da Silva et al., 2002, 2012; Iniesta et al., 2002; Yeramian et al., 2006a,b; Wanasen et al., 2007).

The M1 and M2 type macrophages differ in the induction of CAT2 expression and L-arginine uptake in BALB/c and C57BL/6 mice. The natural deletion of a region in the $\mathrm{CAT} 2 \mathrm{~B}$-coding gene promoter of C57BL/6 macrophages impairs CAT2B expression and reduces L-arginine uptake, increasing the resistance to
Leishmania infection compared to $\mathrm{BALB} / \mathrm{c}$ mice (Sans-Fons et al., 2013). L. amazonensis infection induces the CAT2B, CAT1 and ARG1 expression in BALB/c macrophages enabling the establishment of infection (Muxel et al., 2017). L. major and L. amazonensis repress the NOS2 expression and increase ARG1 activity, regulating the $L$. major growth via regulation of polyamines synthesis (Dixit and Mak, 2002; Kropf et al., 2005). The absence of ARG activity in L. amazonensis (CastilhoMartins et al., 2011; Laranjeira-Silva et al., 2012; Aoki et al., 2017b; Muxel et al., 2017), L. donovani (Boitz et al., 2017), L. mexicana (Roberts et al., 2004) and L. major (Roberts et al., 2004; Reguera et al., 2009) reduced the infectivity. Infection with $\mathrm{La}-\mathrm{arg}^{-}$reduces the levels of CAT2B, CAT1 and ARG1 and allows the expression of NOS2 and NO production in BALB/c macrophages, thereby reducing the infectivity (Laranjeira-Silva et al., 2012; Muxel et al., 2017). In L. amazonensis (LaranjeiraSilva et al., 2012; Muxel et al., 2017) and L. mexicana (Gaur et al., 2007) the absence of ARG activity reduces infectivity via NO overproduction by host macrophages, but not in L. major (Muleme et al., 2009). In addition, the treatment of macrophages with the hormone melatonin, blocks L-arginine uptake via reduction of CAT2B and CAT1 expression, leading to a mild reduction of ARG1 but not of NOS2 expression resulting in a reduction of infectivity of $L$. amazonensis. The importance of L-arginine in the process was shown with the recovered infectivity after putrescine supplementation of parasites treated with melatonin (Laranjeira-Silva et al., 2015). In concordance, L-arginine analog supplementation blocked the parasite growth in infected-macrophages (Iniesta et al., 2001; Wanasen et al., 2007).

CAT1 is the transporter with the highest affinity for L-arginine (Hatzoglou et al., 2004) and it is constitutively expressed in some tissues. Activation of macrophages from BALB/c with M-CSF, LPS, IFN- $\gamma$, IL-10 and IL-4, as well as L-arginine deprivation, does not modify CAT1 expression (Yeramian et al., 2006a,b). Despite this, starvation of mammalian cells increases the stability and translation of Cat1 mRNA (Aulak et al., 1999; Hatzoglou et al., 2004; Bhattacharyya et al., 2006; Lopez et al., 2007).

Some studies have shown that the CAT2 expression in $\mathrm{BALB} / \mathrm{c}$ macrophages is independent of L-arginine availability and ARG1 or NOS2 activity (Hammermann et al., 2000; Yeramian et al., 2006b). In contrast, CAT2 expression and L-arginine uptake in THP-1-derived macrophages and human monocyte-derived macrophages are dependent on L-arginine availability and host arginase activity (Mandal et al., 2017). In addition, the blocking of CAT2 reduces the L-arginine uptake in L. donovani-infected macrophages leading to ARG regulation and decrease of ornithine, spermidine, citrulline and NO levels (Yeramian et al., 2006a; Mandal et al., 2017). Indeed, signals for activation and proliferation of macrophages increase CAT2 levels and L-arginine uptake (Yeramian et al., 2006b). Despite this, spermidine and spermine suppress CAT2B and NOS2 levels and L-arginine uptake in rat alveolar macrophages (Mossner et al., 2001) and inhibit NOS2 activity in J774 macrophages (Szabo et al., 1994a,b). Cells with high ARG1 activity induce the uptake of large amount of L-arginine via CAT2. This may mediate the exchange of ornithine via CAT2 triggering/supplementing 
the neighboring cells (Closs et al., 2006). Spermine inhibits the synthesis of IL- 1, TNF- $\alpha$, IL-6, MIP- $1 \alpha$ and MIP- $1 \beta$ in LPSstimulated human peripheral blood mononuclear cells, which is restored by the polyamine analog 1-4-bis 3-aminopropylpiperazine (BAP) (Zhang et al., 1997, 1999).

Functional characterization of Leishmania ARG, using knockout parasites revealed that the enzyme is essential for in vitro and in vivo proliferation of L. amazonensis (da Silva et al., 2002; Castilho-Martins et al., 2011; Laranjeira-Silva et al., 2012), L. mexicana (Roberts et al., 2004), L. major (Roberts et al., 2004; Reguera et al., 2009) and L. donovani (Boitz et al., 2017). Arginase null L. amazonensis (da Silva et al., 2002; CastilhoMartins et al., 2011; Laranjeira-Silva et al., 2012), L. mexicana (Roberts et al., 2004) and L. major (Roberts et al., 2004; Reguera et al., 2009) presented lower levels of infectivity, with exception of parasite burden in spleen of $L$. donovani infected mice (Boitz et al., 2017), highlighting differences in ARG role in the infection fate of distinct species.

\section{EVASION OF IMMUNE RESPONSE POINTING L-ARGININE METABOLISM}

Since polyamines are essential for Leishmania growth and NO plays an antiparasitic effect, the activity of ARG1 versus NOS2 is a central factor in the immune response leading to host susceptibility or resistance. These enzymes are mutually regulated due to substrate sharing transcriptional and posttranscriptional mechanisms controlling enzyme expression and activity. Leishmania parasites are believed to escape from the macrophage killing response by targeting the L-arginine metabolism, although the molecular mechanisms are not totally understood.

The antiparasitic activity of macrophages could be reduced via inhibition of cytokines and NO, which production is mediated by transcription factors such as NF- $\kappa$, AP-1, STAT and CREB, and reduction in PKC activity, calcium influx and ERK dephosphorylation (Ghosh et al., 2001, 2002; Forget et al., 2005a,b; Gregory and Olivier, 2005; Olivier et al., 2005; BenOthman et al., 2009). L. major and L. amazonensis amastigotes block the nuclear translocation of NF- $\mathrm{B}$ dimer $\mathrm{p} 50 / \mathrm{p} 65$, but increases the dimer p50/p50 translocation, which repress the transcription of pro-inflammatory cytokines (Guizani-Tabbane et al., 2004; Calegari-Silva et al., 2009), NOS2 and CAT2 (Dixit and Mak, 2002) and induces the transcription of IL-10 (GuizaniTabbane et al., 2004; Calegari-Silva et al., 2009).

Post-transcriptional regulation by miRNAs has been recently described as an important component of the polyamines/NO pathways modulation in infected macrophages. MicroRNAs are small non-coding RNAs that are capable of binding to complementary $3^{\prime}$ UTR regions of target mRNA, regulating its stability or translation (Bagga et al., 2005; Lim et al., 2005). L. amazonensis infection increased the expression of some macrophage miRNAs, such as miR-294 and miR-721. These miRNAs interact with $3^{\prime}$ UTR region of Nos 2 mRNA, reducing the enzyme and NO production. Meanwhile, parasites with no ARG activity reduce the expression of those miRNAs and increased NOS2 and NO production, leading to the control of the infection of BALB/c macrophages (Muxel et al., 2017). L. donovani target Dicer1 (RNAse II member family), that could result in post-transcriptional regulation of host mRNAs/miRNA interactions (Ghosh et al., 2013); Leishmaniagp63 cleaved Dicer1 impairing the pre-miR122 processing and maturation to miR-122 preventing the binding to RNA-induced silencing complex (RISC), which guides the interaction with target mRNA and leads to gene expression regulation (Bernstein et al., 2001; Schwarz et al., 2003; Vaucheret et al., 2004; Wang et al., 2009; Ghosh et al., 2013). Furthermore, miR-122 can interact with Cat1 mRNA $3^{\prime}$ UTR regulating its stability and protein levels in stress conditions (Bhattacharyya et al., 2006).

\section{TREATMENTS TARGETING L-ARGININE METABOLISM}

The leishmaniases are neglected tropical diseases affecting primarily underdeveloped regions of the world. They are relatively unattractive for research development, pharmaceutical industry and financial funding. The first-line drug for leishmaniasis treatment recommended by WHO is based on pentavalent antimonial and was described by Vianna (1912). The leishmaniases chemotherapy is complicated because most of the drugs used are expensive, toxic and require long periods of supervised therapy (Murray et al., 2005; Hotez et al., 2008). The pentavalent antimonial (Glucantime and Pentostan) present several side effects and reports of parasite resistance have been described worldwide (Murray et al., 2005). Cases that are unresponsive to antimonial treatment, or patients from Europe or North America are usually treated with amphotericin or PEN, although these drugs also have several side effects (Murray et al., 2005; Croft et al., 2006). The mechanism of action of pentamidine has been related to the disintegration of the kinetoplast and mitochondria, and a collapse in mitochondrial membrane (Croft and Brazil, 1982; Vercesi and Docampo, 1992; Basselin et al., 2002). In L. donovani, pentamidine has been described as a competitive inhibitor of arginine transport (Kandpal et al., 1995) and a non-competitive inhibitor of putrescine and spermidine transport in L. infantum (Reguera et al., 1994), L. donovani and L. mexicana (Basselin et al., 2000). In addition, other compounds have been used for leishmaniasis treatment. Miltefosine was the first effective oral drug developed to treat VL. It has been used in India for decades (Jha et al., 1999), however, an increase in the failure rate has been reported (Sundar et al., 2012; Rijal et al., 2013), possibly by the selection of resistant parasites. Amphotericin B, particularly the liposomal formulation, is also an alternative line for the antimonial treatment and it is associated to binding to the membrane sterol group of Leishmania (Berman et al., 1998; Croft et al., 2006).

Considering the limitations of the currently used chemotherapy and the lack of effective vaccines for the leishmaniases, the identification of new drugs and vaccine approaches for the treatment of leishmaniases is required. A rational strategy for the parasite control can be developed 
based on the identification of fundamental metabolic pathways of the parasite. New potential drug targets based on molecular and biochemical studies involving the following: protein kinases (Naula et al., 2005), glycolytic enzymes (Chawla et al., 2010), sterol synthesis (Urbina et al., 2002; Lorente et al., 2004), purine salvage pathway (Ullman and Carter, 1995; Landfear et al., 2004; Aoki et al., 2009, 2016) and polyamine pathway (Roberts et al., 2004; Reguera et al., 2005) have been described and could be used in future therapies (Sharlow et al., 2009; Siqueira-Neto et al., 2010).

The polyamines pathway could be a promising target, since parasites need the polyamine pathway to replicate and establish the infection in the mammal host (da Silva et al., 2012). Previous description targeting polyamine-based treatment with 1 - $\alpha$-difluoromethylornithine (DFMO) leading to the ODC inhibition in T. brucei is described successful against African sleeping sickness (Van Nieuwenhove et al., 1985). However, the efficacy of DFMO for Leishmania is controversial. Previous studies demonstrate the efficacy for L. donovani, L. infantum and L. guyanensis infections but not for L. major and L. mexicana (Gradoni et al., 1989; Keithly and Fairlamb, 1989). Furthermore, other studies describe the DFMO inefficacy against Leishmania (Kaur et al., 1986).

Other ODC inhibitors have been described, such as 3-aminooxy-1-aminopropane (APA), an isosteric analog of putrescine, effective in $L$. donovani promastigotes and amastigotes (Singh et al., 2007). L. donovani AdoMetDC was the target for $\mathrm{A} 5^{\prime}-((\mathrm{Z})$-4-amino-2-butenyl)methylamino)-5' deoxyadenosine (MDL73811) and overexpression of AdoMetDC in L. donovani promastigotes conferred resistance to MDL73811, but not to pentamidine, berenil and mitoguazone (MGBG), inhibitors of dAdoMet activity in vitro (Roberts et al., 2002). The overexpression of ODC, AdoMetDC and SpdS in L. donovani promastigotes conferred resistance to DFMO, MDL73811, and n-butylamine (Roberts et al., 2007). Interestingly, the resistance to antimonial drugs correlates with ODC overexpression in L. tarentolae (Haimeur et al., 1999). Nitric oxide synthase inhibitor L-NGmonomethylarginine (L-NMMA) reduce the levels of NO and increase the infectivity of L. infantum in human macrophages (Panaro et al., 2001). Controversially, some polyamines analogs or inhibitors could be cytotoxic for host cells because of blocking the polyamines production. In this way, further studies must explore a specific drug for polyamines enzymes of the parasite.

Gene knockout experiments have also been used to demonstrate the importance of some genes in the polyamine pathway as essential for parasite growth (Laranjeira-Silva et al., 2012; Laranjeira-Silva and Floeter-Winter, 2014). ARG, ODC, AdoMetDC or SpdS null mutant knockout lines have been providing important data on the dependence on supplementation

\section{REFERENCES}

Abello, N., Kerstjens, H. A., Postma, D. S., and Bischoff, R. (2009). Protein tyrosine nitration: selectivity, physicochemical and biological consequences, denitration, with the substrates for parasite replication in L. donovani, L. major, L. mexicana and L. amazonensis (Laranjeira-Silva et al., 2012; Laranjeira-Silva and Floeter-Winter, 2014; Boitz et al., 2017; Aoki et al., 2017b; Roberts and Ullman, 2017). In addition, in vivo and in vitro infections present lower infection index, demonstrating how this pathway can a promisor target chemotherapy.

Another fact that may be considered for new treatment strategy is the fundamental differences between the parasite and its host. A promising target can be the amino acids uptake. As mentioned before, L-arginine uptake in macrophages is mediated by CAT (Closs et al., 2004). In contrast, Leishmania has a complex and specific machinery to take up this amino acid. L-arginine uptake in Leishmania is mediated by AAP3 (Darlyuk et al., 2009; Castilho-Martins et al., 2011; Aoki et al., 2017a). Since ARG and AAP3 are localized in the plasma membrane and compartmentalized in the glycosome of promastigotes and axenic amastigotes (da Silva et al., 2012; Aoki et al., 2017a), a strategy to control Leishmania infection could be focused on the inhibition of L-arginine flux by both plasmatic membrane and glycosome of the parasite.

\section{CONCLUDING REMARKS}

In this review, we elucidate the arginine and polyamine in Leishmania infection by both host and parasite. The amino acid availability defines the fate of infection for immune response control or for parasite replication. Activated macrophages produce leishmanicidal molecules, such as NO, that lead to parasite killing, whereas induce ARG expression to parasite replication. These two fates of infection use L-arginine as a common substrate for their enzymatic activities.

\section{AUTHOR CONTRIBUTIONS}

SM, JA, JF, and LF-W wrote the original article. JF designed the figures. SM, JA, JF, RZ, SA, KM, RV, LF-W, and ML-S revised the article.

\section{FUNDING}

This work was supported by grants from the Conselho Nacional de Desenvolvimento Científico e Tecnológico (CNPq, http: //www.cnpq.br: 307587/2014-2.) and Fundação de Amparo à Pesquisa do Estado de São Paulo (FAPESP, http://www. fapesp.br: 2014/50717-1, 2016/19815-2). FAPESP fellowship: SA (2015/25942-4), JF (2016/22896-4), and JA (2016/10461-3). LF-W is a research fellowship from CNPq (307587/2014-2).

and proteomics methods for the identification of tyrosine-nitrated proteins. J. Proteome Res. 8, 3222-3238. doi: 10.1021/pr900039c

Acuña, S. M., Aoki, J. I., Laranjeira da Silva, M. F., Zampieri, R. A., Fernandes, J. C., Muxel, S. M., et al. (2017). Arginase expression modulates nitric oxide 
production in Leishmania (Leishmania) amazonensis. PLOS ONE 12:e0187186. doi: 10.1371/journal.pone. 0187186

Akerman, M., Shaked-Mishan, P., Mazareb, S., Volpin, H., and Zilberstein, D. (2004). Novel motifs in amino acid permease genes from Leishmania. Biochem. Biophys. Res. Commun. 325, 353-366. doi: 10.1016/j.bbrc.2004.09.212

Akira, S., and Sato, S. (2003). Toll-like receptors and their signaling mechanisms. Scand. J. Infect. Dis. 35, 555-562. doi: 10.1080/00365540310015683

Alvar, J., Vélez, I. D., Bern, C., Herrero, M., Desjeux, P., Cano, J., et al. (2012). Leishmaniasis worldwide and global estimates of its incidence. PLOS ONE 7:e35671. doi: 10.1371/journal.pone.0035671

Aoki, J. I., Coelho, A. C., Muxel, S. M., Zampieri, R. A., Sanchez, E. M., Nerland, A. H., et al. (2016). Characterization of a novel endoplasmic reticulum protein involved in tubercidin resistance in Leishmania major. PLOS Negl. Trop. Dis. 10:e0004972. doi: 10.1371/journal.pntd.0004972

Aoki, J. I., Muxel, S. M., Zampieri, R. A., Acuna, S. M., Fernandes, J. C. R., Vanderlinde, R. H., et al. (2017a). L-arginine availability and arginase activity: characterization of amino acid permease 3 in Leishmania amazonensis. PLOS Negl. Trop. Dis. 11:e0006025. doi: 10.1371/journal.pntd.0006025

Aoki, J. I., Muxel, S. M., Zampieri, R. A., Laranjeira da Silva, M. F., Muller, K. E., Nerland, A., et al. (2017b). RNA-seq transcriptional profiling of Leishmania amazonensis reveals an arginase-dependent gene expression regulation. PLOS Negl. Trop. Dis. 11:e0006026. doi: 10.1371/journal.pntd.0006026

Aoki, J. I., Yamashiro-Kanashiro, E. H., Ramos, D. C. C., and Cotrim, P. C. (2009). Efficacy of the tubercidin antileishmania action associated with an inhibitor of the nucleoside transport. Parasitol. Res. 104, 223-228. doi: 10.1007/s00436-008$1177-\mathrm{z}$

Ashford, R. W. (2000). The leishmaniases as emerging and reemerging zoonoses. Int. J. Parasitol. 30, 1269-1281. doi: 10.1016/S0020-7519(00)00136-3

Aulak, K. S., Mishra, R., Zhou, L., Hyatt, S. L., de Jonge, W., Lamers, W., et al. (1999). Post-transcriptional regulation of the arginine transporter Cat-1 by amino acid availability. J. Biol. Chem. 274, 30424-30432. doi: 10.1074/jbc.274. 43.30424

Bacellar, O., D'Oliveira, A. Jr., Jeronimo, S., and Carvalho, E. M. (2000). IL-10 and IL-12 are the main regulatory cytokines in visceral leishmaniasis. Cytokine 12, 1228-1231. doi: 10.1006/cyto.2000.0694

Bachrach, U., Brem, S., Wertman, S. B., Schnur, L. F., and Greenblatt, C. L. (1979). Leishmania spp.: cellular levels and synthesis of polyamines during growth cycles. Exp. Parasitol. 48, 457-463. doi: 10.1016/0014-4894(79)90130-9

Bagga, S., Bracht, J., Hunter, S., Massirer, K., Holtz, J., Eachus, R., et al. (2005). Regulation by let-7 and lin-4 miRNAs results in target mRNA degradation. Cell 122, 553-563. doi: 10.1016/j.cell.2005.07.031

Balafanova, Z., Bolli, R., Zhang, J., Zheng, Y., Pass, J. M., Bhatnagar, A., et al. (2002). Nitric oxide (NO) induces nitration of protein kinase Cepsilon (PKCepsilon), facilitating PKCepsilon translocation via enhanced PKCepsilonRACK2 interactions: a novel mechanism of NO-triggered activation of PKCepsilon. J. Biol. Chem. 277, 15021-15027. doi: 10.1074/jbc.M112451200

Basselin, M., Coombs, G. H., and Barrett, M. P. (2000). Putrescine and spermidine transport in Leishmania. Mol. Biochem. Parasitol. 109, 37-46. doi: 10.1016/ S0166-6851(00)00234-6

Basselin, M., Denise, H., Coombs, G. H., and Barrett, M. P. (2002). Resistance to pentamidine in Leishmania mexicana involves exclusion of the drug from the mitochondrion. Antimicrob. Agents Chemother. 46, 3731-3738. doi: 10.1128/ AAC.46.12.3731-3738.2002

Belkaid, Y., Butcher, B., and Sacks, D. L. (1998). Analysis of cytokine production by inflammatory mouse macrophages at the single-cell level: selective impairment of IL-12 induction in Leishmania-infected cells. Eur. J. Immunol. $28, \quad 1389-1400 . \quad$ doi:10.1002/(SICI)1521-4141(199804)28:04<1389::AIDIMMU1389>3.0.CO;2-1

Ben-Othman, R., Dellagi, K., and Guizani-Tabbane, L. (2009). Leishmania major parasites induced macrophage tolerance: implication of MAPK and NF-kappaB pathways. Mol. Immunol. 46, 3438-3444. doi: 10.1016/j.molimm.2009.05.337

Berman, J. D., Badaro, R., Thakur, C. P., Wasunna, K. M., Behbehani, K., Davidson, R., et al. (1998). Efficacy and safety of liposomal amphotericin B (AmBisome) for visceral leishmaniasis in endemic developing countries. Bull. World Health Organ. 76, 25-32.

Bernstein, E., Caudy, A. A., Hammond, S. M., and Hannon, G. J. (2001). Role for a bidentate ribonuclease in the initiation step of RNA interference. Nature 409, 363-366. doi: $10.1038 / 35053110$
Bhattacharyya, S., Ghosh, S., Jhonson, P. L., Bhattacharya, S. K., and Majumdar, S. (2001). Immunomodulatory role of interleukin-10 in visceral leishmaniasis: defective activation of protein kinase C-mediated signal transduction events. Infect. Immunity 69, 1499-1507. doi: 10.1128/IAI.69.3.1499-1507.2001

Bhattacharyya, S. N., Habermacher, R., Martine, U., Closs, E. I., and Filipowicz, W. (2006). Relief of microRNA-mediated translational repression in human cells subjected to stress. Cell 125, 1111-1124. doi: 10.1016/j.cell.2006.04.031

Boitz, J. M., Gilroy, C. A., Olenyik, T. D., Paradis, D., Perdeh, J., Dearman, K., et al. (2017). Arginase is essential for survival of Leishmania donovani promastigotes but not intracellular amastigotes. Infect. Immunity 85:e0554-16. doi: 10.1128/ IAI.00554-16

Calegari-Silva, T. C., Pereira, R. M., De-Melo, L. D., Saraiva, E. M., Soares, D. C., Bellio, M., et al. (2009). NF-kappaB-mediated repression of iNOS expression in Leishmania amazonensis macrophage infection. Immunol. Lett. 127, 19-26. doi: 10.1016/j.imlet.2009.08.009

Camargo, E. P., Coelho, J. A., Moraes, G., and Figueiredo, E. N. (1978). Trypanosoma spp., Leishmania spp. and Leptomonas spp.: enzymes of ornithine-arginine metabolism. Exp. Parasitol. 46, 141-144. doi: 10.1016/00144894(78) $90125-\mathrm{X}$

Carrera, L., Gazzinelli, R. T., Badolato, R., Hieny, S., Muller, W., Kuhn, R., et al. (1996). Leishmania promastigotes selectively inhibit interleukin 12 induction in bone marrow-derived macrophages from susceptible and resistant mice. J. Exp. Med. 183, 515-526. doi: 10.1084/jem.183.2.515

Castilho-Martins, E. A., Canuto, G. A., Muxel, S. M., da Silva, M. F., Floeter-Winter, L. M., Del Aguila, C., et al. (2015). Capillary electrophoresis reveals polyamine metabolism modulation in Leishmania (Leishmania) amazonensis wild type and arginase knockout mutants under arginine starvation. Electrophoresis doi: 10.1002/elps.201500114 [Epub ahead of print].

Castilho-Martins, E. A., Laranjeira da Silva, M. F., dos Santos, M. G., Muxel, S. M., and Floeter-Winter, L. M. (2011). Axenic Leishmania amazonensis promastigotes sense both the external and internal arginine pool distinctly regulating the two transporter-coding genes. PLOS ONE 6:e27818. doi: 10.1371/ journal.pone. 0027818

Chawla, B., Jhingran, A., Singh, S., Tyagi, N., Park, M. H., Srinivasan, N., et al. (2010). Identification and characterization of a novel deoxyhypusine synthase in Leishmania donovani. J. Biol. Chem. 285, 453-463. doi: 10.1074/jbc.M109. 048850

Closs, E. I., Boissel, J. P., Habermeier, A., and Rotmann, A. (2006). Structure and function of cationic amino acid transporters (CATs). J. Membr. Biol. 213, 67-77. doi: 10.1007/s00232-006-0875-7

Closs, E. I., Simon, A., Vekony, N., and Rotmann, A. (2004). Plasma membrane transporters for arginine. J. Nutr. 134, 2752S-2759S; discussion 2765S-2767S.

Colasanti, M., Gradoni, L., Mattu, M., Persichini, T., Salvati, L., Venturini, G., et al. (2002). Molecular bases for the anti-parasitic effect of NO (Review). Int. J. Mol. Med. 9, 131-134. doi: 10.3892/ijmm.9.2.131

Corraliza, I. M., Soler, G., Eichmann, K., and Modolell, M. (1995). Arginase induction by suppressors of nitric oxide synthesis (IL-4, IL-10 and PGE2) in murine bone-marrow-derived macrophages. Biochem. Biophys. Res. Commu. 206, 667-673. doi: 10.1006/bbrc.1995.1094

Croft, S. L., and Brazil, R. P. (1982). Effect of pentamidine isethionate on the ultrastructure and morphology of Leishmania mexicana amazonensis in vitro. Ann. Trop. Med. Parasitol. 76, 37-43. doi: 10.1080/00034983.1982.11687502

Croft, S. L., Sundar, S., and Fairlamb, A. H. (2006). Drug resistance in leishmaniasis. Clin. Microbiol. Rev. 19, 111-126. doi: 10.1128/CMR.19.1.111-126.2006

da Silva, E. R., Castilho, T. M., Pioker, F. C., Tomich de Paula Silva, C. H., and Floeter-Winter, L. M. (2002). Genomic organisation and transcription characterisation of the gene encoding Leishmania (Leishmania) amazonensis arginase and its protein structure prediction. Int. J. Parasitol. 32, 727-737. doi: $10.1016 / 50020-7519(02) 00002-4$

da Silva, E. R., da Silva, M. F., Fischer, H., Mortara, R. A., Mayer, M. G., Framesqui, K., et al. (2008). Biochemical and biophysical properties of a highly active recombinant arginase from Leishmania (Leishmania) amazonensis and subcellular localization of native enzyme. Mol. Biochem. Parasitol. 159, 104-111. doi: 10.1016/j.molbiopara.2008.02.011

da Silva, M. F., Zampieri, R. A., Muxel, S. M., Beverley, S. M., and FloeterWinter, L. M. (2012). Leishmania amazonensis arginase compartmentalization in the glycosome is important for parasite infectivity. PLOS ONE 7:e34022. doi: 10.1371 /journal.pone.0034022 
D’Antonio, E. L., Ullman, B., Roberts, S. C., Dixit, U. G., Wilson, M. E., Hai, Y., et al. (2013). Crystal structure of arginase from Leishmania mexicana and implications for the inhibition of polyamine biosynthesis in parasitic infections. Arch. Biochem. Biophys. 535, 163-176. doi: 10.1016/j.abb.2013. 03.015

Darlyuk, I., Goldman, A., Roberts, S. C., Ullman, B., Rentsch, D., and Zilberstein, D. (2009). Arginine homeostasis and transport in the human pathogen Leishmania donovani. J. Biol. Chem. 284, 19800-19807. doi: 10.1074/jbc.M901066200

de Freitas Balanco, J. M., Moreira, M. E., Bonomo, A., Bozza, P. T., AmaranteMendes, G., Pirmez, C., et al. (2001). Apoptotic mimicry by an obligate intracellular parasite downregulates macrophage microbicidal activity. Curr. Biol. 11, 1870-1873. doi: 10.1016/S0960-9822(01)00563-2

de Veer, M. J., Curtis, J. M., Baldwin, T. M., DiDonato, J. A., Sexton, A., McConville, M. J., et al. (2003). MyD88 is essential for clearance of Leishmania major: possible role for lipophosphoglycan and Toll-like receptor 2 signaling. Eur. J. Immunol. 33, 2822-2831. doi: 10.1002/eji.200324128

Dixit, V., and Mak, T. W. (2002). NF-kappaB signaling. Many roads lead to Madrid. Cell 111, 615-619.

dos Santos, M. G., Muxel, S. M., Zampieri, R. A., Pomorski, T. G., and FloeterWinter, L. M. (2013). Transbilayer dynamics of phospholipids in the plasma membrane of the Leishmania genus. PLOS ONE 8:e55604. doi: 10.1371/journal. pone.0055604

El Kasmi, K. C., Qualls, J. E., Pesce, J. T., Smith, A. M., Thompson, R. W., HenaoTamayo, M., et al. (2008). Toll-like receptor-induced arginase 1 in macrophages thwarts effective immunity against intracellular pathogens. Nat. Immunol. 9, 1399-1406. doi: 10.1038/ni.1671

Faria, M. S., Reis, F. C., and Lima, A. P. (2012). Toll-like receptors in leishmania infections: guardians or promoters? J. Parasitol. Res. 2012:930257. doi: 10.1155/ 2012/930257

Fiebig, M., Kelly, S., and Gluenz, E. (2015). Comparative life cycle transcriptomics revises Leishmania mexicana genome annotation and links a chromosome duplication with parasitism of vertebrates. PLOS Pathog. 11:e1005186. doi: 10.1371/journal.ppat.1005186

Flandin, J. F., Chano, F., and Descoteaux, A. (2006). RNA interference reveals a role for TLR2 and TLR3 in the recognition of Leishmania donovani promastigotes by interferon-gamma-primed macrophages. Eur. J. Immunol. 36, 411-420. doi: 10.1002/eji.200535079

Forget, G., Gregory, D. J., and Olivier, M. (2005a). Proteasome-mediated degradation of STAT1alpha following infection of macrophages with Leishmania donovani. J. Biol. Chem. 280, 30542-30549.

Forget, G., Matte, C., Siminovitch, K. A., Rivest, S., Pouliot, P., and Olivier, M. (2005b). Regulation of the Leishmania-induced innate inflammatory response by the protein tyrosine phosphatase SHP-1. Eur. J. Immunol. 35, 1906-1917.

Franca-Costa, J., Van Weyenbergh, J., Boaventura, V. S., Luz, N. F., MaltaSantos, H., Oliveira, M. C., et al. (2015). Arginase I, polyamine, and prostaglandin E2 pathways suppress the inflammatory response and contribute to diffuse cutaneous leishmaniasis. J. Infect. Dis. 211, 426-435. doi: 10.1093/ infdis/jiu455

Frankenburg, S., Leibovici, V., Mansbach, N., Turco, S. J., and Rosen, G. (1990). Effect of glycolipids of Leishmania parasites on human monocyte activity. Inhibition by lipophosphoglycan. J. Immunol. 145, 4284-4289.

Gaur, U., Roberts, S. C., Dalvi, R. P., Corraliza, I., Ullman, B., and Wilson, M. E. (2007). An effect of parasite-encoded arginase on the outcome of murine cutaneous leishmaniasis. J. Immunol. 179, 8446-8453. doi: 10.4049/jimmunol. 179.12.8446

Genestra, M., de Souza, W. J., Cysne-Finkelstein, L., and Leon, L. L. (2003). Comparative analysis of the nitric oxide production by Leishmania sp. Med. Microbiol. Immunol. 192, 217-223. doi: 10.1007/s00430-003-0176-z

Genestra, M., Guedes-Silva, D., Souza, W. J., Cysne-Finkelstein, L., SoaresBezerra, R. J., Monteiro, F. P., et al. (2006a). Nitric oxide synthase (NOS) characterization in Leishmania amazonensis axenic amastigotes. Arch. Med. Res. 37, 328-333.

Genestra, M., Souza, W. J., Guedes-Silva, D., Machado, G. M., CysneFinkelstein, L., Bezerra, R. J., et al. (2006b). Nitric oxide biosynthesis by Leishmania amazonensis promastigotes containing a high percentage of metacyclic forms. Arch. Microbiol. 185, 348-354.

Geraldo, M. V., Silber, A. M., Pereira, C. A., and Uliana, S. R. (2005). Characterisation of a developmentally regulated amino acid transporter gene from Leishmania amazonensis. FEMS Microbiol. Lett. 242, 275-280. doi: 10.1016/j.femsle.2004.11.030

Ghalib, H. W., Whittle, J. A., Kubin, M., Hashim, F. A., El-Hassan, A. M., Grabstein, K. H., et al. (1995). IL-12 enhances Th1-type responses in human Leishmania donovani infections. J. Immunol. 154, 4623-4629.

Ghosh, J., Bose, M., Roy, S., and Bhattacharyya, S. N. (2013). Leishmania donovani targets Dicer1 to downregulate miR-122, lower serum cholesterol, and facilitate murine liver infection. Cell Host Microbe 13, 277-288. doi: 10.1016/j.chom. 2013.02.005

Ghosh, S., Bhattacharyya, S., Das, S., Raha, S., Maulik, N., Das, D. K., et al. (2001). Generation of ceramide in murine macrophages infected with Leishmania donovani alters macrophage signaling events and aids intracellular parasitic survival. Mol. Cell Biochem. 223, 47-60. doi: 10.1023/A:10179966 09928

Ghosh, S., Bhattacharyya, S., Sirkar, M., Sa, G. S., Das, T., Majumdar, D., et al. (2002). Leishmania donovani suppresses activated protein 1 and NF- $\kappa$ B activation in host macrophages via ceramide generation: involvement of extracellular signal-regulated kinase. Infect. Immunity 70, 6828-6838. doi: 10.1128/IAI.70.12.6828-6838.2002

Gilroy, C., Olenyik, T., Roberts, S. C., and Ullman, B. (2011). Spermidine synthase is required for virulence of Leishmania donovani. Infect. Immunity 79, 2764-2769. doi: 10.1128/IAI.00073-11

Goldman-Pinkovich, A., Balno, C., Strasser, R., Zeituni-Molad, M., Bendelak, K., Rentsch, D., et al. (2016). An arginine deprivation response pathway is induced in Leishmania during macrophage invasion. PLOS Pathog. 12:e1005494. doi: 10.1371/journal.ppat.1005494

Goodman, J. L., Wang, S., Alam, S., Ruzicka, F. J., Frey, P. A., and Wedekind, J. E. (2004). Ornithine cyclodeaminase: structure, mechanism of action, and implications for the mu-crystallin family. Biochemistry 43, 13883-13891. doi: $10.1021 /$ bi048207i

Gradoni, L., Iorio, M. A., Gramiccia, M., and Orsini, S. (1989). In vivo effect of eflornithine (DFMO) and some related compounds on Leishmania infantum preliminary communication. Farmaco 44, 1157-1166.

Green, S. J., Crawford, R. M., Hockmeyer, J. T., Meltzer, M. S., and Nacy, C. A. (1990a). Leishmania major amastigotes initiate the L-arginine-dependent killing mechanism in IFN-gamma-stimulated macrophages by induction of tumor necrosis factor-alpha. J. Immunol. 145, 4290-4297.

Green, S. J., Meltzer, M. S., Hibbs, J. B. Jr., and Nacy, C. A. (1990b). Activated macrophages destroy intracellular Leishmania major amastigotes by an L-arginine-dependent killing mechanism. J. Immunol. 144, 278-283.

Gregory, D. J., and Olivier, M. (2005). Subversion of host cell signalling by the protozoan parasite Leishmania. Parasitology 130(Suppl.), S27-S35. doi: 10.1017/S0031182005008139

Guizani-Tabbane, L., Ben-Aissa, K., Belghith, M., Sassi, A., and Dellagi, K. (2004). Leishmania major amastigotes induce p50/c-Rel NF-kappa B transcription factor in human macrophages: involvement in cytokine synthesis. Infect. Immunity 72, 2582-2589. doi: 10.1128/IAI.72.5.2582-2589.2004

Haimeur, A., Guimond, C., Pilote, S., Mukhopadhyay, R., Rosen, B. P., Poulin, R., et al. (1999). Elevated levels of polyamines and trypanothione resulting from overexpression of the ornithine decarboxylase gene in arsenite-resistant Leishmania. Mol. Microbiol. 34, 726-735. doi: 10.1046/j.1365-2958.1999. 01634.x

Hammermann, R., Dreissig, M. D., Mossner, J., Fuhrmann, M., Berrino, L., Gothert, M., et al. (2000). Nuclear factor-kappaB mediates simultaneous induction of inducible nitric-oxide synthase and Up-regulation of the cationic amino acid transporter CAT-2B in rat alveolar macrophages. Mol. Pharmacol. 58, 1294-1302.

Hart, D. T., Baudhuin, P., Opperdoes, F. R., and de Duve, C. (1987). Biogenesis of the glycosome in Trypanosoma brucei: the synthesis, translocation and turnover of glycosomal polypeptides. EMBO J. 6, 1403-1411.

Hatzigeorgiou, D. E., Geng, J., Zhu, B., Zhang, Y., Liu, K., Rom, W. N., et al. (1996). Lipophosphoglycan from Leishmania suppresses agonist-induced interleukin 1 beta gene expression in human monocytes via a unique promoter sequence. Proc. Natl. Acad. Sci. U.S.A. 93, 14708-14713. doi: 10.1073/pnas.93.25. 14708

Hatzoglou, M., Fernandez, J., Yaman, I., and Closs, E. (2004). Regulation of cationic amino acid transport: the story of the CAT-1 transporter. Annu. Rev. Nutr. 24, 377-399. doi: 10.1146/annurev.nutr.23.011702.073120 
Hess, D. T., and Stamler, J. S. (2012). Regulation by S-nitrosylation of protein post-translational modification. J. Biol. Chem. 287, 4411-4418. doi: 10.1074/jbc. R111.285742

Hotez, P. J., Bottazzi, M. E., Franco-Paredes, C., Ault, S. K., and Periago, M. R. (2008). The neglected tropical diseases of Latin America and the Caribbean: a review of disease burden and distribution and a roadmap for control and elimination. PLOS Negl. Trop. Dis. 2:e300. doi: 10.1371/journal.pntd.00 00300

Iniesta, V., Gomez-Nieto, L. C., and Corraliza, I. (2001). The inhibition of arginase by $\mathrm{N}$ (omega)-hydroxy-L-arginine controls the growth of Leishmania inside macrophages. J. Exp. Med. 193, 777-784. doi: 10.1084/jem.193.6.777

Iniesta, V., Gomez-Nieto, L. C., Molano, I., Mohedano, A., Carcelen, J., Miron, C., et al. (2002). Arginase I induction in macrophages, triggered by Th2-type cytokines, supports the growth of intracellular Leishmania parasites. Parasite Immunol. 24, 113-118. doi: 10.1046/j.1365-3024.2002.00444.x

Janeway, C. A. Jr., and Medzhitov, R. (2002). Innate immune recognition. Annu. Rev. Immunol. 20, 197-216. doi: 10.1146/annurev.immunol.20.083001.084359

Jha, T. K., Sundar, S., Thakur, C. P., Bachmann, P., Karbwang, J., Fischer, C., et al. (1999). Miltefosine, an oral agent, for the treatment of Indian visceral leishmaniasis. N. Engl. J. Med. 341, 1795-1800. doi: 10.1056/ NEJM199912093412403

Ji, Y., Neverova, I., Van Eyk, J. E., and Bennett, B. M. (2006). Nitration of tyrosine 92 mediates the activation of rat microsomal glutathione s-transferase by peroxynitrite. J. Biol. Chem. 281, 1986-1991. doi: 10.1074/jbc.M509480200

Kandpal, M., Fouce, R. B., Pal, A., Guru, P. Y., and Tekwani, B. L. (1995) Kinetics and molecular characteristics of arginine transport by Leishmania donovani promastigotes. Mol. Biochem. Parasitol. 71, 193-201. doi: 10.1016/ 0166-6851(95)00042-Y

Kane, M. M., and Mosser, D. M. (2001). The role of IL-10 in promoting disease progression in leishmaniasis. J. Immunol. 166, 1141-1147. doi: 10.4049/ jimmunol.166.2.1141

Kanyo, Z. F., Scolnick, L. R., Ash, D. E., and Christianson, D. W. (1996). Structure of a unique binuclear manganese cluster in arginase. Nature 383, 554-557. doi: $10.1038 / 383554 \mathrm{a} 0$

Kaul, S., Sharma, S. S., and Mehta, I. K. (2008). Free radical scavenging potential of L-proline: evidence from in vitro assays. Amino Acids 34, 315-320. doi: 10.1007/s00726-006-0407-x

Kaur, K., Emmett, K., McCann, P. P., Sjoerdsma, A., and Ullman, B. (1986). Effects of DL-alpha-difluoromethylornithine on Leishmania donovani promastigotes. J. Protozool. 33, 518-521. doi: 10.1111/j.1550-7408.1986.tb05654.x

Kavoosi, G., Ardestani, S. K., Kariminia, A., and Alimohammadian, M. H. (2010). Leishmania major lipophosphoglycan: discrepancy in Toll-like receptor signaling. Exp. Parasitol. 124, 214-218. doi: 10.1016/j.exppara.2009.09.017

Kawasaki, H., Shigenaga, A., Uda, M., Baba, T., Ogawa, H., Takamori, K., et al. (2011). Nitration of tryptophan in ribosomal proteins is a novel posttranslational modification of differentiated and naive PC12 cells. Nitric Oxide 25, 176-182. doi: 10.1016/j.niox.2011.05.005

Keithly, J. S., and Fairlamb, A. H. (1989). "Inhibition of Leishmania species by $\alpha$-difluoromethylornithine," in Leishmaniasis. NATO ASI Series (Series A: Life Sciences), ed. D. T. Hart (Boston, MA: Springer).

Krassner, S. M., and Flory, B. (1971). Essential amino acids in the culture of Leishmania tarentolae. J. Parasitol. 57, 917-920. doi: 10.2307/3277829

Krauth-Siegel, R. L., Meiering, S. K., and Schmidt, H. (2003). The parasite-specific trypanothione metabolism of trypanosoma and leishmania. Biol. Chem. 384, 539-549. doi: 10.1515/BC.2003.062

Kropf, P., Fuentes, J. M., Fahnrich, E., Arpa, L., Herath, S., Weber, V., et al. (2005). Arginase and polyamine synthesis are key factors in the regulation of experimental leishmaniasis in vivo. FASEB J. 19, 1000-1002. doi: 10.1096/fj.043416 fje

Lakhal-Naouar, I., Jardim, A., Strasser, R., Luo, S., Kozakai, Y., Nakhasi, H. L., et al. (2012). Leishmania donovani argininosuccinate synthase is an active enzyme associated with parasite pathogenesis. PLOS Negl. Trop. Dis. 6:e1849. doi: 10.1371/journal.pntd.0001849

Landfear, S. M. (2011). Nutrient transport and pathogenesis in selected parasitic protozoa. Eukaryot. Cell 10, 483-493. doi: 10.1128/EC.00287-10

Landfear, S. M., Ullman, B., Carter, N. S., and Sanchez, M. A. (2004). Nucleoside and nucleobase transporters in parasitic protozoa. Eukaryot. Cell 3, 245-254. doi: 10.1128/EC.3.2.245-254.2004
Laranjeira-Silva, M. F., and Floeter-Winter, L. M. (2014). “Arginase in Leishmania," in Proteins and Proteomics of Leishmania and Trypanosoma, eds A. Santos, M. Branquinha, C. D’Avila-Levy, L. Kneipp, and C. Sodré (Berlin: Springer), 103-118. doi: 10.1007/978-94-007-7305-9_4

Laranjeira-Silva, M. F., Zampieri, R. A., Muxel, S. M., Beverley, S. M., and FloeterWinter, L. M. (2012). Leishmania amazonensis arginase compartmentalization in the glycosome is important for parasite infectivity. PLOS ONE 7:e34022. doi: 10.1371/journal.pone.0034022

Laranjeira-Silva, M. F., Zampieri, R. A., Muxel, S. M., Floeter-Winter, L. M., and Markus, R. P. (2015). Melatonin attenuates Leishmania (L.) amazonensis infection by modulating arginine metabolism. J. Pineal Res. 59, 478-487. doi: 10.1111/jpi.12279

Liew, F. Y., Li, Y., Moss, D., Parkinson, C., Rogers, M. V., and Moncada, S. (1991). Resistance to Leishmania major infection correlates with the induction of nitric oxide synthase in murine macrophages. Eur. J. Immunol. 21, 3009-3014. doi: 10.1002/eji.1830211216

Liew, F. Y., Millott, S., Parkinson, C., Palmer, R. M., and Moncada, S. (1990). Macrophage killing of Leishmania parasite in vivo is mediated by nitric oxide from L-arginine. J. Immunol. 144, 4794-4797.

Lim, L. P., Lau, N. C., Garrett-Engele, P., Grimson, A., Schelter, J. M., Castle, J., et al. (2005). Microarray analysis shows that some microRNAs downregulate large numbers of target mRNAs. Nature 433, 769-773. doi: 10.1038/nature03315

Loeuillet, C., Banuls, A. L., and Hide, M. (2016). Study of Leishmania pathogenesis in mice: experimental considerations. Parasites Vectors 9:144. doi: 10.1186/ s13071-016-1413-9

Lopez, A. B., Wang, C., Huang, C. C., Yaman, I., Li, Y., Chakravarty, K., et al. (2007). A feedback transcriptional mechanism controls the level of the arginine/lysine transporter cat-1 during amino acid starvation. Biochem. J. 402, 163-173. doi: 10.1042/BJ20060941

Lorente, S. O., Rodrigues, J. C., Jiménez Jiménez, C., Joyce-Menekse, M., Rodrigues, C., Croft, S. L., et al. (2004). Novel azasterols as potential agents for treatment of leishmaniasis and trypanosomiasis. Antimicrob. Agents Chemother. 48, 2937-2950. doi: 10.1128/AAC.48.8.2937-2950.2004

Mandal, A., Das, S., Kumar, A., Roy, S., Verma, S., Ghosh, A. K., et al. (2017). L-arginine uptake by cationic amino acid transporter promotes intramacrophage survival of Leishmania donovani by enhancing arginase-mediated polyamine synthesis. Front. Immunol. 8:839. doi: 10.3389/fimmu.2017.00839

Mandal, A., Das, S., Roy, S., Ghosh, A. K., Sardar, A. H., Verma, S., et al. (2016). Deprivation of L-arginine induces oxidative stress mediated apoptosis in Leishmania donovani promastigotes: contribution of the polyamine pathway. PLOS Negl. Trop. Dis. 10:e0004373. doi: 10.1371/journal.pntd.00 04373

Marsden, P. D. (1986). Mucosal leishmaniasis (“espundia” Escomel, 1911). Trans. R. Soc. Trop. Med. Hyg. 80, 859-876. doi: 10.1016/0035-9203(86)90243-9

Martinez-Ruiz, A., Cadenas, S., and Lamas, S. (2011). Nitric oxide signaling: classical, less classical, and nonclassical mechanisms. Free Radic. Biol. Med. 51, 17-29. doi: 10.1016/j.freeradbiomed.2011.04.010

Matte, C., Maion, G., Mourad, W., and Olivier, M. (2001). Leishmania donovaniinduced macrophages cyclooxygenase-2 and prostaglandin E2 synthesis. Parasite Immunol. 23, 177-184. doi: 10.1046/j.1365-3024.2001.00372.x

McConville, M. J. (2016). Metabolic crosstalk between Leishmania and the macrophage host. Trends Parasitol. 32, 666-668. doi: 10.1016/j.pt.2016.05.005

McConville, M. J., de Souza, D., Saunders, E., Likic, V. A., and Naderer, T. (2007). Living in a phagolysosome; metabolism of Leishmania amastigotes. Trends Parasitol. 23, 368-375. doi: 10.1016/j.pt.2007.06.009

McConville, M. J., Saunders, E. C., Kloehn, J., and Dagley, M. J. (2015). Leishmania carbon metabolism in the macrophage phagolysosome- feast or famine? F1000Res. 4:938. doi: 10.12688/f1000research.6724.1

Medzhitov, R. (2007). Recognition of microorganisms and activation of the immune response. Nature 449, 819-826. doi: 10.1038/nature06246

Melby, P. C., Andrade-Narvaez, F. J., Darnell, B. J., Valencia-Pacheco, G., Tryon, V. V., and Palomo-Cetina, A. (1994). Increased expression of proinflammatory cytokines in chronic lesions of human cutaneous leishmaniasis. Infect. Immunity 62, 837-842.

Mossner, J., Hammermann, R., and Racke, K. (2001). Concomitant downregulation of $\mathrm{L}$-arginine transport and nitric oxide (NO) synthesis in rat alveolar macrophages by the polyamine spermine. Pulm. Pharmacol. Ther. 14, 297-305. doi: 10.1006/pupt.2001.0297 
Mukhopadhyay, R., and Madhubala, R. (1995). Effects of bis(benzyl)polyamine analogs on Leishmania donovani promastigotes. Exp. Parasitol. 81, 39-46. doi: 10.1006/expr.1995.1090

Muleme, H. M., Reguera, R. M., Berard, A., Azinwi, R., Jia, P., Okwor, I. B., et al. (2009). Infection with arginase-deficient Leishmania major reveals a parasite number-dependent and cytokine-independent regulation of host cellular arginase activity and disease pathogenesis. J. Immunol. 183, 8068-8076. doi: 10.4049/jimmunol.0803979

Murray, H. W., Berman, J. D., Davies, C. R., and Saravia, N. G. (2005). Advances in leishmaniasis. Lancet 366, 1561-1577. doi: 10.1016/S0140-6736(05) 67629-5

Muxel, S. M., Laranjeira-Silva, M. F., Zampieri, R. A., and Floeter-Winter, L. M. (2017). Leishmania (Leishmania) amazonensis induces macrophage miR-294 and miR-721 expression and modulates infection by targeting NOS2 and L-arginine metabolism. Sci. Rep. 7:44141. doi: 10.1038/srep44141

Naderer, T., and McConville, M. J. (2008). The Leishmania-macrophage interaction: a metabolic perspective. Cell. Microbiol. 10, 301-308. doi: 10.1111/ j.1462-5822.2007.01096.x

Nakagawa, H., Komai, N., Takusagawa, M., Miura, Y., Toda, T., Miyata, N., et al. (2007). Nitration of specific tyrosine residues of cytochrome $\mathrm{C}$ is associated with caspase-cascade inactivation. Biol. Pharm. Bull. 30, 15-20. doi: 10.1248/bpb. 30.15

Nakagawa, R., Naka, T., Tsutsui, H., Fujimoto, M., Kimura, A., Abe, T., et al. (2002). SOCS-1 participates in negative regulation of LPS responses. Immunity 17, 677-687. doi: 10.1016/S1074-7613(02)00449-1

Nasseri, M., and Modabber, F. Z. (1979). Generalized infection and lack of delayed hypersensitivity in BALB/c mice infected with Leishmania tropica major. Infect. Immunity 26, 611-614.

Nathan, C., and Shiloh, M. U. (2000). Reactive oxygen and nitrogen intermediates in the relationship between mammalian hosts and microbial pathogens. Proc. Natl. Acad. Sci. U.S.A. 97, 8841-8848. doi: 10.1073/pnas.97.16.8841

Naula, C., Parsons, M., and Mottram, J. C. (2005). Protein kinases as drug targets in trypanosomes and Leishmania. Biochim. Biophys. Acta 1754, 151-159. doi: 10.1016/j.bbapap.2005.08.018

Olivier, M., Gregory, D. J., and Forget, G. (2005). Subversion mechanisms by which Leishmania parasites can escape the host immune response: a signaling point of view. Clin. Microbiol. Rev. 18, 293-305. doi: 10.1128/CMR.18.2.293-305.2005

O'Neill, L. A., Golenbock, D., and Bowie, A. G. (2013). The history of Tolllike receptors - redefining innate immunity. Nat. Rev. Immunol. 13, 453-460. doi: $10.1038 /$ nri3446

Opperdoes, F. R. (1987). Compartmentation of carbohydrate metabolism in trypanosomes. Annu. Rev. Microbiol. 41, 127-151. doi: 10.1146/annurev.mi.41. 100187.001015

Opperdoes, F. R., and Szikora, J. P. (2006). In silico prediction of the glycosomal enzymes of Leishmania major and trypanosomes. Mol. Biochem. Parasitol. 147, 193-206. doi: 10.1016/j.molbiopara.2006.02.010

O'Quinn, P. R., Knabe, D. A., and Wu, G. (2002). Arginine catabolism in lactating porcine mammary tissue. J. Anim. Sci. 80, 467-474. doi: 10.2527/2002.802467x

Oza, S. L., Shaw, M. P., Wyllie, S., and Fairlamb, A. H. (2005). Trypanothione biosynthesis in Leishmania major. Mol. Biochem. Parasitol. 139, 107-116. doi: 10.1016/j.molbiopara.2004.10.004

Panaro, M. A., Brandonisio, O., Sisto, M., Acquafredda, A., Leogrande, D., Fumarola, L., et al. (2001). Nitric oxide production by Leishmania-infected macrophages and modulation by prostaglandin E2. Clin. Exp. Med. 1, 137-143. doi: 10.1007/s10238-001-8025-0

Pekarova, M., and Lojek, A. (2015). The crucial role of L-arginine in macrophage activation: what you need to know about it. Life Sci. 137, 44-48. doi: 10.1016/j. lfs.2015.07.012

Pereira, M., Soares, C., Canuto, G. A., Tavares, M. F., Colli, W., and Alves, M. J. (2015). Down regulation of NO signaling in Trypanosoma cruzi upon parasite-extracellular matrix interaction: changes in protein modification by nitrosylation and nitration. PLOS Negl. Trop. Dis. 9:e0003683. doi: 10.1371/ journal.pntd.0003683

Rath, M., Muller, I., Kropf, P., Closs, E. I., and Munder, M. (2014). Metabolism via arginase or nitric oxide synthase: two competing arginine pathways in macrophages. Front. Immunol. 5:532. doi: 10.3389/fimmu.2014.00532

Reguera, R., Balaña Fouce, R., Cubria, J. C., Alvarez Bujidos, M. L., and Ordoñez, D. (1994). Putrescine uptake inhibition by aromatic diamidines in Leishmania infantum promastigotes. Biochem. Pharmacol. 47, 1859-1866. doi: 10.1016/ 0006-2952(94)90316-6

Reguera, R. M., Balana-Fouce, R., Showalter, M., Hickerson, S., and Beverley, S. M. (2009). Leishmania major lacking arginase (ARG) are auxotrophic for polyamines but retain infectivity to susceptible BALB/c mice. Mol. Biochem. Parasitol. 165, 48-56. doi: 10.1016/j.molbiopara.2009.01.001

Reguera, R. M., Tekwani, B. L., and Balana-Fouce, R. (2005). Polyamine transport in parasites: a potential target for new antiparasitic drug development. Comp. Biochem. Physiol. Toxicol. Pharmacol. 140, 151-164. doi: 10.1016/j.cca.2005. 02.006

Ribeiro-Gomes, F. L., Roma, E. H., Carneiro, M. B., Doria, N. A., Sacks, D. L., and Peters, N. C. (2014). Site-dependent recruitment of inflammatory cells determines the effective dose of Leishmania major. Infect. Immun. 82, 2713-2727. doi: 10.1128/IAI.01600-13

Rijal, S., Ostyn, B., Uranw, S., Rai, K., Bhattarai, N. R., Dorlo, T. P., et al. (2013). Increasing failure of miltefosine in the treatment of kala-azar in Nepal and the potential role of parasite drug resistance, reinfection, or noncompliance. Clin. Infect. Dis. 56, 1530-1538. doi: 10.1093/cid/cit102

Roberts, S., and Ullman, B. (2017). Parasite polyamines as pharmaceutical targets. Curr. Pharm. Des. 23, 3325-3341. doi: 10.2174/1381612823666170601101644

Roberts, S. C., Jiang, Y., Gasteier, J., Frydman, B., Marton, L. J., Heby, O., et al. (2007). Leishmania donovani polyamine biosynthetic enzyme overproducers as tools to investigate the mode of action of cytotoxic polyamine analogs. Antimicrob. Agents Chemother. 51, 438-445. doi: 10.1128/AAC. 01193-06

Roberts, S. C., Jiang, Y., Jardim, A., Carter, N. S., Heby, O., and Ullman, B. (2001). Genetic analysis of spermidine synthase from Leishmania donovani. Mol. Biochem. Parasitol. 115, 217-226. doi: 10.1016/S0166-6851(01)00293-6

Roberts, S. C., Scott, J., Gasteier, J. E., Jiang, Y., Brooks, B., Jardim, A., et al. (2002). S-adenosylmethionine decarboxylase from Leishmania donovani. Molecular, genetic, and biochemical characterization of null mutants and overproducers. J. Biol. Chem. 277, 5902-5909. doi: 10.1074/jbc.M110118200

Roberts, S. C., Tancer, M. J., Polinsky, M. R., Gibson, K. M., Heby, O., and Ullman, B. (2004). Arginase plays a pivotal role in polyamine precursor metabolism in Leishmania. Characterization of gene deletion mutants. J. Biol. Chem. 279, 23668-23678. doi: 10.1074/jbc.M402042200

Sacks, D., and Kamhawi, S. (2001). Molecular aspects of parasite-vector and vector-host interactions in leishmaniasis. Annu. Rev. Microbiol. 55, 453-483. doi: 10.1146/annurev.micro.55.1.453

Sans-Fons, M. G., Yeramian, A., Pereira-Lopes, S., Santamaria-Babi, L. F., Modolell, M., Lloberas, J., et al. (2013). Arginine transport is impaired in $\mathrm{C} 57 \mathrm{Bl} / 6$ mouse macrophages as a result of a deletion in the promoter of Slc7a2 (CAT2), and susceptibility to Leishmania infection is reduced. J. Infect. Dis. 207, 1684-1693. doi: 10.1093/infdis/jit084

Santos, C. S., Boaventura, V., Ribeiro Cardoso, C., Tavares, N., Lordelo, M. J., Noronha, A., et al. (2013). $\mathrm{CD}^{+}$granzyme $\mathrm{B}^{+}$-mediated tissue injury vs. $\mathrm{CD}^{+}{ }^{+} \mathrm{IFNgamma}^{+}$-mediated parasite killing in human cutaneous leishmaniasis. J. Investig. Dermatol. 133, 1533-1540. doi: 10.1038/jid. 2013.4

Sardar, A. H., Jardim, A., Ghosh, A. K., Mandal, A., Das, S., Saini, S., et al. (2016). Genetic manipulation of Leishmania donovani to explore the involvement of argininosuccinate synthase in oxidative stress management. PLOS Negl. Trop. Dis. 10:e0004308. doi: 10.1371/journal.pntd.0004308

Sarkar, A., Mandal, G., Singh, N., Sundar, S., and Chatterjee, M. (2009). Flow cytometric determination of intracellular non-protein thiols in Leishmania promastigotes using 5-chloromethyl fluorescein diacetate. Exp. Parasitol. 122, 299-305. doi: 10.1016/j.exppara.2009.04.012

Sarkar, A., Saha, P., Mandal, G., Mukhopadhyay, D., Roy, S., Singh, S. K., et al. (2011). Monitoring of intracellular nitric oxide in leishmaniasis: its applicability in patients with visceral leishmaniasis. Cytometry A 79, 35-45. doi: 10.1002/ cyto.a. 21001

Schnur, L. F., Bachrach, U., Greenblatt, C. L., and Ben Joseph, M. (1979). Polyamine synthesis and levels during the growth and replication of Leishmania tropica minor and Leishmania aethiopica. FEBS Lett. 106, 202-206. doi: 10.1016/00145793(79)80728-0

Schwarz, D. S., Hutvagner, G., Du, T., Xu, Z., Aronin, N., and Zamore, P. D. (2003). Asymmetry in the assembly of the RNAi enzyme complex. Cell 115, 199-208. doi: 10.1016/S0092-8674(03)00759-1 
Séguin, O., and Descoteaux, A. (2016). Leishmania, the phagosome, and host responses: the journey of a parasite. Cell Immunol. 309, 1-6. doi: 10.1016/j. cellimm.2016.08.004

Shaked-Mishan, P., Suter-Grotemeyer, M., Yoel-Almagor, T., Holland, N., Zilberstein, D., and Rentsch, D. (2006). A novel high-affinity arginine transporter from the human parasitic protozoan Leishmania donovani. Mol. Microbiol. 60, 30-38. doi: 10.1111/j.1365-2958.2006.05060.x

Shanware, N. P., Mullen, A. R., DeBerardinis, R. J., and Abraham, R. T. (2011). Glutamine: pleiotropic roles in tumor growth and stress resistance. J. Mol. Med. 89, 229-236. doi: 10.1007/s00109-011-0731-9

Sharlow, E. R., Close, D., Shun, T., Leimgruber, S., Reed, R., Mustata, G., et al. (2009). Identification of potent chemotypes targeting Leishmania major using a high-throughput, low-stringency, computationally enhanced, small molecule screen. PLOS Negl. Trop. Dis. 3:e540. doi: 10.1371/journal.pntd.00 00540

Singh, S., Mukherjee, A., Khomutov, A. R., Persson, L., Heby, O., Chatterjee, M., et al. (2007). Antileishmanial effect of 3-aminooxy-1-aminopropane is due to polyamine depletion. Antimicrob. Agents Chemother. 51, 528-534. doi: 10.1128/ AAC.01055-06

Siqueira-Neto, J. L., Song, O. R., Oh, H., Sohn, J. H., Yang, G., Nam, J., et al. (2010). Antileishmanial high-throughput drug screening reveals drug candidates with new scaffolds. PLOS Negl. Trop. Dis. 4:e675. doi: 10.1371/journal.pntd.0000675

Souza, J. M., Choi, I., Chen, Q., Weisse, M., Daikhin, E., Yudkoff, M., et al. (2000). Proteolytic degradation of tyrosine nitrated proteins. Arch. Biochem. Biophys. 380, 360-366. doi: 10.1006/abbi.2000.1940

Srivastava, A., Singh, N., Mishra, M., Kumar, V., Gour, J. K., Bajpai, S., et al. (2012). Identification of TLR inducing Th1-responsive Leishmania donovani amastigote-specific antigens. Mol. Cell Biochem. 359, 359-368. doi: 10.1007/ s11010-011-1029-5

Steiger, R. F., and Meshnick, S. R. (1977). Amino-acid and glucose utilization of Leishmania donovani and L. braziliensis. Trans. R. Soc. Trop. Med. Hyg. 71, 441-443. doi: 10.1016/0035-9203(77)90049-9

Steiger, R. F., and Steiger, E. (1977). Cultivation of Leishmania donovani and Leishmania braziliensis in defined media: nutritional requirements. J. Protozool. 24, 437-441. doi: 10.1111/j.1550-7408.1977.tb04771.x

Sundar, S., Singh, A., Rai, M., Prajapati, V. K., Singh, A. K., Ostyn, B., et al. (2012). Efficacy of miltefosine in the treatment of visceral leishmaniasis in India after a decade of use. Clin. Infect. Dis. 55, 543-550. doi: 10.1093/cid/cis474

Szabo, C., Southan, G. J., Thiemermann, C., and Vane, J. R. (1994a). The mechanism of the inhibitory effect of polyamines on the induction of nitric oxide synthase: role of aldehyde metabolites. Br. J. Pharmacol. 113, 757-766.

Szabo, C., Southan, G. J., Wood, E., Thiemermann, C., and Vane, J. R. (1994b). Inhibition by spermine of the induction of nitric oxide synthase in J774.2 macrophages: requirement of a serum factor. Br. J. Pharmacol. 112, 355-356.

Teixeira, D. E., Benchimol, M., Rodrigues, J. C., Crepaldi, P. H., Pimenta, P. F., and de Souza, W. (2013). The cell biology of Leishmania: how to teach using animations. PLOS Pathog. 9:e1003594. doi: 10.1371/journal.ppat.1003594

Temporal, R. M., Cysne-Finkelstein, L., Echevarria, A., Silva-Goncalves, A. J., Leon, L. L., and Genestra, M. S. (2005). Amidine derivatives and Leishmania amazonensis: an evaluation of the effect of nitric oxide (NO) production on the parasite-macrophage interaction. J. Enzyme Inhib. Med. Chem. 20, 13-18. doi: 10.1080/14756360400015207

Tovar, J., Wilkinson, S., Mottram, J. C., and Fairlamb, A. H. (1998). Evidence that trypanothione reductase is an essential enzyme in Leishmania by targeted replacement of the tryA gene locus. Mol. Microbiol. 29, 653-660. doi: 10.1046/j. 1365-2958.1998.00968.x

Ullman, B., and Carter, D. (1995). Hypoxanthine-guanine phosphoribosy ltransferase as a therapeutic target in protozoal infections. Infect. Agents Dis. 4, 29-40.

Urbina, J. A., Concepcion, J. L., Rangel, S., Visbal, G., and Lira, R. (2002). Squalene synthase as a chemotherapeutic target in Trypanosoma cruzi and Leishmania mexicana. Mol. Biochem. Parasitol. 125, 35-45. doi: 10.1016/S0166-6851(02) 00206-2

Van Nieuwenhove, S., Schechter, P. J., Declercq, J., Boné, G., Burke, J., and Sjoerdsma, A. (1985). Treatment of gambiense sleeping sickness in the Sudan with oral DFMO (DL-alpha-difluoromethylornithine), an inhibitor of ornithine decarboxylase; first field trial. Trans. R. Soc. Trop. Med. Hyg. 79, 692-698. doi: 10.1016/0035-9203(85)90195-6 van Zandbergen, G., Bollinger, A., Wenzel, A., Kamhawi, S., Voll, R., Klinger, M., et al. (2006). Leishmania disease development depends on the presence of apoptotic promastigotes in the virulent inoculum. Proc. Natl. Acad. Sci. U.S.A. 103, 13837-13842. doi: 10.1073/pnas.0600843103

Vaucheret, H., Vazquez, F., Crete, P., and Bartel, D. P. (2004). The action of ARGONAUTE1 in the miRNA pathway and its regulation by the miRNA pathway are crucial for plant development. Genes Dev. 18, 1187-1197. doi: $10.1101 /$ gad.1201404

Vercesi, A. E., and Docampo, R. (1992). $\mathrm{Ca}^{2+}$ transport by digitonin-permeabilized Leishmania donovani. Effects of $\mathrm{Ca}^{2+}$, pentamidine and WR-6026 on mitochondrial membrane potential in situ. Biochem. J. 284(Pt 2), 463-467. doi: 10.1042/bj2840463

Vianna, G. (1912). Tratamento da leishmaniose tegumentar por injeções intravenosas de tártaro emético. Anais do $7^{\circ}$ Congresso Brasileiro de Medicina e Cirurgia 4, 426-428.

Vieira, L. L. (1998). pH and volume homeostasis in trypanosomatids: current views and perspectives. Biochim. Biophys. Acta 1376, 221-241. doi: 10.1016/S03044157(98)00007-0

Vieira, L. L., and Cabantchik, Z. I. (1995). Amino acid uptake and intracellular accumulation in Leishmania major promastigotes are largely determined by an $\mathrm{H}^{+}$-pump generated membrane potential. Mol. Biochem. Parasitol. 75, 15-23. doi: 10.1016/0166-6851(95)02505-7

Vieira, L. Q., Goldschmidt, M., Nashleanas, M., Pfeffer, K., Mak, T., and Scott, P. (1996). Mice lacking the TNF receptor p55 fail to resolve lesions caused by infection with Leishmania major, but control parasite replication. J. Immunol. 157, 827-835.

Wakabayashi, Y., Iwashima, A., Yamada, E., and Yamada, R. (1991a). Enzymological evidence for the indispensability of small intestine in the synthesis of arginine from glutamate. II. N-acetylglutamate synthase. Arch. Biochem. Biophys. 291, 9-14. doi: 10.1016/0003-9861(91)90098-4

Wakabayashi, Y., Yamada, E., Hasegawa, T., and Yamada, R. (1991b). Enzymological evidence for the indispensability of small intestine in the synthesis of arginine from glutamate. I. Pyrroline-5-carboxylate synthase. Arch. Biochem. Biophys. 291, 1-8.

Wanasen, N., MacLeod, C. L., Ellies, L. G., and Soong, L. (2007). L-arginine and cationic amino acid transporter $2 \mathrm{~B}$ regulate growth and survival of Leishmania amazonensis amastigotes in macrophages. Infect. Immunity 75, 2802-2810. doi: 10.1128/IAI.00026-07

Wanasen, N., and Soong, L. (2008). L-arginine metabolism and its impact on host immunity against Leishmania infection. Immunol. Res. 41, 15-25. doi: 10.1007/s12026-007-8012-y

Wanderley, J. L., Pinto da Silva, L. H., Deolindo, P., Soong, L., Borges, V. M., Prates, D. B., et al. (2009). Cooperation between apoptotic and viable metacyclics enhances the pathogenesis of Leishmaniasis. PLOS ONE 4:e5733. doi: 10.1371/ journal.pone.0005733

Wang, B., Li, S., Qi, H. H., Chowdhury, D., Shi, Y., and Novina, C. D. (2009). Distinct passenger strand and mRNA cleavage activities of human Argonaute proteins. Nat. Struct. Mol. Biol. 16, 1259-1266. doi: 10.1038/nsmb.1712

Weingartner, A., Kemmer, G., Muller, F. D., Zampieri, R. A., Gonzaga dos Santos, M., Schiller, J., et al. (2012). Leishmania promastigotes lack phosphatidylserine but bind annexin $\mathrm{V}$ upon permeabilization or miltefosine treatment. PLOS ONE 7:e42070. doi: 10.1371/journal.pone.0042070

Weinheber, N., Wolfram, M., Harbecke, D., and Aebischer, T. (1998). Phagocytosis of Leishmania mexicana amastigotes by macrophages leads to a sustained suppression of IL-12 production. Eur. J. Immunol. 28, 2467-2477. doi: 10.1002/ (SICI)1521-4141(199808)28:08<2467::AID-IMMU2467>3.0.CO;2-1

WHO (2017). Leishmaniasis. Geneva: WHO.

Wilhelm, P., Ritter, U., Labbow, S., Donhauser, N., Rollinghoff, M., Bogdan, C., et al. (2001). Rapidly fatal leishmaniasis in resistant C57BL/6 mice lacking TNF. J. Immunol. 166, 4012-4019. doi: 10.4049/jimmunol.166.6.4012

Wu, G., Bazer, F. W., Datta, S., Johnson, G. A., Li, P., Satterfield, M. C., et al. (2008). Proline metabolism in the conceptus: implications for fetal growth and development. Amino Acids 35, 691-702. doi: 10.1007/s00726-008-0052-7

Wu, G., and Morris, S. M. Jr. (1998). Arginine metabolism: nitric oxide and beyond. Biochem. J. 336(Pt 1), 1-17. doi: 10.1042/bj3360001

Yang, Z., Mosser, D. M., and Zhang, X. (2007). Activation of the MAPK, ERK, following Leishmania amazonensis infection of macrophages. J. Immunol. 178, 1077-1085. doi: 10.4049/jimmunol.178.2.1077 
Yeramian, A., Martin, L., Arpa, L., Bertran, J., Soler, C., McLeod, C., et al. (2006a). Macrophages require distinct arginine catabolism and transport systems for proliferation and for activation. Eur. J. Immunol. 36, 1516-1526.

Yeramian, A., Martin, L., Serrat, N., Arpa, L., Soler, C., Bertran, J., et al. (2006b). Arginine transport via cationic amino acid transporter 2 plays a critical regulatory role in classical or alternative activation of macrophages. J. Immunol. 176, 5918-5924.

Yoshida, N., and Camargo, E. P. (1978). Ureotelism and ammonotelism in trypanosomatids. J. Bacteriol. 136, 1184-1186.

Zhang, M., Borovikova, L. V., Wang, H., Metz, C., and Tracey, K. J. (1999). Spermine inhibition of monocyte activation and inflammation. Mol. Med. 5, 595-605.

Zhang, M., Caragine, T., Wang, H., Cohen, P. S., Botchkina, G., Soda, K., et al. (1997). Spermine inhibits proinflammatory cytokine synthesis in human mononuclear cells: a counterregulatory mechanism that restrains the immune response. J. Exp. Med. 185, 1759-1768. doi:10.1084/jem.185.10. 1759
Zilberstein, D. (1993). Transport of nutrients and ions across membranes of trypanosomatid parasites. Adv. Parasitol. 32, 261-291. doi: 10.1016/S0065308X(08)60209-2

Zilberstein, D., and Gepstein, A. (1993). Regulation of L-proline transport in Leishmania donovani by extracellular pH. Mol. Biochem. Parasitol. 61, 197-205. doi: 10.1016/0166-6851(93)90066-7

Conflict of Interest Statement: The authors declare that the research was conducted in the absence of any commercial or financial relationships that could be construed as a potential conflict of interest.

Copyright (c) 2018 Muxel, Aoki, Fernandes, Laranjeira-Silva, Zampieri, Acuña, Müller, Vanderlinde and Floeter-Winter. This is an open-access article distributed under the terms of the Creative Commons Attribution License (CC BY). The use, distribution or reproduction in other forums is permitted, provided the original author(s) or licensor are credited and that the original publication in this journal is cited, in accordance with accepted academic practice. No use, distribution or reproduction is permitted which does not comply with these terms. 